\title{
Melanocortin Signaling in the Brainstem Influences Vagal Outflow to the Stomach
}

\author{
Janell Richardson, ${ }^{1}$ Maureen T. Cruz, ${ }^{3}$ Usnish Majumdar, ${ }^{1}$ Amanda Lewin, ${ }^{1}$ Kathryn A. Kingsbury, ${ }^{1}$ Ghazaul Dezfuli, ${ }^{3}$ \\ Stefano Vicini, ${ }^{1}$ Joseph G. Verbalis, ${ }^{2}$ Kenneth L. Dretchen, ${ }^{1}$ Richard A. Gillis, ${ }^{1}$ and Niaz Sahibzada ${ }^{1}$ \\ Departments of ${ }^{1}$ Pharmacology and Physiology and ${ }^{2}$ Medicine and ${ }^{3}$ Interdisciplinary Program in Neuroscience, Georgetown University Medical Center, \\ Washington, DC 20057
}

Activation of melanocortin 4 receptors (MC4-Rs) in brain nuclei associated with food intake profoundly influences consummatory behavior. Of these nuclei, the dorsal motor vagal nucleus (DMV), which has a dense concentration of MC4-Rs, is an important regulator of gastric tone and motility. Hence, the present study sought to examine the role of MC4-Rs in this nucleus on these activities. Using an in vivo approach, MC4-R agonists, melanotan-II (MT-II) or $\alpha$-melanocyte stimulating hormone ( $\alpha$-MSH), were unilaterally microinjected into the DMV of rats, and their effects were noted on gastric activity. MT-II decreased phasic contractions, whereas $\alpha$-MSH increased their amplitude. Both effects were blocked by the MC4-R antagonist SHU9119 or by ipsilateral vagotomy. Microinjection of the agonists (MT-II and $\alpha$-MSH) into the overlying nucleus of the solitary tract (NTS), an important component of "vago-vagal" gastric circuitry, decreased phasic contractions. In addition, $\alpha$-MSH reduced gastric tone and mean arterial blood pressure. To study the underlying mechanisms of the effect of MC4-R stimulation on gastric activity, electrophysiological recordings were made from labeled DMV antrum neurons in rat pups and $M C 4-R^{-/-}$mice. Bath application of MT-II or $\alpha$-MSH significantly reduced spontaneous action potentials (but not in $M C 4-R^{-1-}$ mice). However, in low-calcium ACSF, MT-II decreased neuronal firing, whereas $\alpha$-MSH increased it. These effects mirror those of our in vivo DMV studies. Altogether, our novel findings show that activation of MC4-Rs in the brainstem, particularly in the medial NTS by the endogenous peptide $\alpha$-MSH, modulates gastric activity, which may have physiological relevance for food intake and gastric function.

\section{Introduction}

The importance of melanocortin 4 receptors (MC4-Rs) in energy balance has been documented extensively (Grill and Kaplan, 2002; Cone, 2005; Morton et al., 2006; De Jonghe et al., 2011). Their distribution in the brain (Mountjoy et al., 1994; Kishi et al., 2003; Liu et al., 2003) corresponds well with nuclei that are essential for the regulation of feeding and gastrointestinal function, such as those of the hypothalamus and brainstem (Gillis et al., 1989; Rogers et al., 1996; Giraudo et al., 1998; De Jonghe et al., 2011). In the brainstem, particularly noteworthy is the dense expression of MC4-R mRNA in the dorsal motor vagal nucleus (DMV) (Mountjoy et al., 1994; Kishi et al., 2003; Liu et al., 2003), which is restricted medially to the rostral two-thirds of the nucleus (Kishi et al., 2003).

To date, despite the prominent distribution of MC4-Rs in the DMV, information regarding their role at this nucleus is sparse. Activation or inhibition of these receptors at the DMV or in its vicinity is reported to decrease or increase food intake, respec-

\footnotetext{
Received Feb. 19, 2013; revised June 11, 2013; accepted June 13, 2013.

Author contributions: J.R., S.V., J.G.V., K.L.D., R.A.G., and N.S. designed research; J.R., M.T.C., U.M., A.L., K.A.K., G.D., and N.S. performed research; J.R., U.M., K.A.K., R.A.G., and N.S. analyzed data; J.R., S.V., R.A.G., and N.S. wrote the paper.

This work was supported by National Institutes of Health Grant R01 DK57105.

The authors declare no competing financial interests.

Correspondence should be addressed to Dr. Niaz Sahibzada, Department of Pharmacology and Physiology, Georgetown University Medical Center, Washington, DC 20057. E-mail: sahibzan@georgetown.edu.

DOI:10.1523/JNEUROSCI.0780-13.2013

Copyright $\odot 2013$ the authors $\quad 0270-6474 / 13 / 3313286-14 \$ 15.00 / 0$
}

tively (Grill et al., 1998; Williams et al., 2000; Zheng et al., 2005, 2010). However, it is difficult to separate the extent and manner by which the DMV influences food intake from that of the overlying nucleus of the solitary tract (NTS); activation of MC4-Rs in both nuclei is reported to reduce food intake (Williams et al., 2000; Zheng et al., 2010). This is surprising considering that the two nuclei differentially affect gastric motility (Ferreira et al., 2002; Cruz et al., 2007), which is thought to have great relevance for food intake (Janssen et al., 2011). Furthermore, reactivation of MC4-R signaling in preganglionic parasympathetic DMV neurons has little if any effect on feeding behavior (Rossi et al., 2011). These disparate reports led us to ask the following: if MC4-Rs in the DMV are not directly pivotal to the control of food intake, then what purposes do they serve in this nucleus? A potential role envisaged for these receptors was that they might regulate gastric motility by influencing vagal outflow to the stomach. The DMV serves, among other functions, as an important regulator of gastric motility (Gillis et al., 1989; Rogers et al., 1996; Ferreira et al., 2002; Cruz et al., 2007).

Because MC4-R mRNA expression is mainly restricted to the medial portion of the DMV (Mountjoy et al., 1994; Kishi et al., 2003; Liu et al., 2003), we hypothesized that MC4-R activation in this nucleus would primarily influence phasic contractions. This was extrapolated from neuroanatomical observations, which note that preganglionic neurons in the DMV are topographically organized such that those projecting to the antropyloric region of the stomach are more medially situated than those that project to its fundus (Shapiro and Miselis, 1985; Pagani et al., 1988; Pearson 
et al., 2007, 2011). The antropyloric region is characterized by strong phasic contractions that help to grind food (Armitage and Dean, 1963; el-Sharkawy et al., 1978; Gillis et al., 1989; Lüdtke et al., 1991; Rogers et al., 1996).

\section{Materials and Methods}

\section{Gastric physiology}

Experiments were performed on male Sprague Dawley rats weighing 300-400 g (Harlan Laboratories) in accordance with the National Institutes of Health guidelines for use of animals in research and with the approval of the Georgetown University Animal Care and Use Committee.

Surgical preparation. Before all experiments, food was withheld overnight, whereas water was provided ad libitum. Animals were anesthetized with an intraperitoneal injection containing a mixture of urethane $(800$ $\mathrm{mg} / \mathrm{kg}$ ) and $\alpha$-chloralose $(60 \mathrm{mg} / \mathrm{kg}$ ) dissolved in $0.9 \%$ saline. Body temperature was monitored by a rectal thermometer and maintained at $37 \pm$ $1^{\circ} \mathrm{C}$ with an infrared heat lamp. To minimize brain swelling, all animals that underwent neurosurgery were pretreated with dexamethasone $(0.8$ $\mathrm{mg}$, s.c.). After depth of anesthesia was confirmed by lack of pedal and corneal reflexes, rats were intubated via the trachea after a tracheotomy to maintain an open airway and to institute artificial respiration when necessary. Next, the carotid artery and the jugular vein were cannulated with polyethylene tubing (PE-50) for monitoring blood pressure and for systemic infusion of drugs, respectively. Blood pressure was monitored by a pressure transducer that was coupled to a PowerLab data acquisition system (ADInstruments). Both cervical vagi were carefully isolated from each carotid artery on either side and looped with a 5-0 silk thread for later avulsion during the experiment.

Subsequent to vessel cannulation, a laparotomy was performed to expose the stomach. An intragastric balloon (made from a latex condom that was $\sim 3.0 \mathrm{~cm}$ long) was inserted into the stomach via the fundus and positioned in the distal region of the antrum, secured in place by a purse string suture. The balloon was inflated (with warm water, $\sim 1.2-1.4 \mathrm{ml}$ ) to produce a baseline pressure of $6-12 \mathrm{mmHg}$, which was measured by a pressure transducer (sensitivity, $5 \mu \mathrm{V} \cdot \mathrm{V}^{-1} \cdot \mathrm{mmHg}^{-1}$ ) that was connected to it in a manner similar to that described above for monitoring blood pressure. At the end of the procedure, the abdominal cavity was closed using a 0-0 chromic gut suture.

Microinjection procedure. To gain access to the dorsal medulla, the rats were positioned in a stereotaxic apparatus (David Kopf Instruments). A limited dorsal craniotomy was performed to expose the medulla, and the underlying dura and pia were cut and reflected. The caudal tip of the area postrema, the calamus scriptorius (CS), was viewed as a reference point for determining the microinjection coordinates.

Microinjection of drugs was accomplished by a double-barreled glass pipette (inner diameter, $9.3 \mu \mathrm{m}$; outer diameter, 35-80 $\mu \mathrm{m}$; FHC) that was connected to PE-50 tubing. All microinjections were given into either the DMV or the medial NTS (mNTS) at a $30^{\circ}$ angle from the perpendicular. Drugs were administered within $5-10 \mathrm{~s}$ in a volume of $30 \mathrm{nl}$ by hand-controlled pressure as determined by a calibration tape (Formaline 9006B) affixed to the micropipette. Stereotaxic coordinates for injection into the DMV were as follows: anteroposterior, $+0.4-0.8 \mathrm{~mm}$ rostral to CS; mediolateral, $0.2-0.3 \mathrm{~mm}$ lateral to the midline; and dorsoventral, $0.4-0.6 \mathrm{~mm}$ ventral to the dorsal surface of the medulla. Coordinates for the mNTS were as follows: $+0.5-0.9 \mathrm{~mm}$ rostral to CS; $0.3-0.5 \mathrm{~mm}$ lateral to the midline; and $0.2-0.4 \mathrm{~mm}$ ventral to the dorsal surface of the medulla.

Both blood and intragastric pressure data were acquired using the PowerLab data acquisition system (ADInstruments) that was connected to an Apple G5 computer.

Histological verification of pipette tracks. At the end of each experiment, the rat was killed with an overdose of the anesthetic mixture mentioned above. The brain was removed and placed in a fixative-cryoprotectant solution that was composed of $4 \%$ phosphate-buffered paraformaldehyde and $10 \%$ sucrose $(0.1 \mathrm{M} ; \mathrm{pH} 7.4)$ for at least $48 \mathrm{~h}$. The brainstem was dissected and cut on a cryostat into $50 \mu \mathrm{m}$ coronal sections, which were mounted serially onto gelatinized slides and stained with cresyl violet
$(0.8 \%)$. The locations of the microinjection pipette tracks were identified using the atlas of Paxinos and Watson (1998). To document microinjection sites, microphotographs and camera lucida drawings were made of each pipette track.

Data analyses. Analysis of the intragastric pressure recordings was completed offline using the Chart (ADInstruments) and Prism (GraphPad Software) software packages. To account for respiration and various other signal artifacts, all experimental recordings were initially filtered using a root mean square (RMS; $2 \mathrm{~s}$ moving window) algorithm. The peak effect of the drug was selected within $5 \mathrm{~min}$ of the injection in which the largest change from baseline was observed (usually a 1-3 min segment). The time-to-peak was taken at the point of injection to a period in which the maximum drug effect was observed. The time-to-steady-state was taken as the point of injection to a value that did not change significantly over a $15 \mathrm{~min}$ period. To determine a change in the amplitude of gastric phasic contractions, an algorithm for calculating average peak-topeak values was used. This algorithm was used because gastric phasic contractions have a low frequency of occurrence (e.g., the antrum displays 1.3-5.3 cycles/min; Lentle et al., 2010). Moreover, this low frequency of gastric phasic contractions did not allow for calculating the area under the curve because of distortion in signal of many of the gastric contractions along the $x$-axis. This was particularly noticeable after microinjection of the MC4-R agonist melanotan-II (MT-II) that significantly decreased the amplitude of the contractions. Nevertheless, because of the natural variance in the amplitude of gastric contractions, the average peak-to-peak values proved to be a uniform method by which to compare all datasets. However, after analysis of peak-to-peak parameters of baseline values and those measured after drug administration, it was found that differences in an animal's intrinsic activity could introduce considerable variance in the results. To solve this problem, a druginduced response in each animal was normalized to its baseline value, which was displayed as a percentage change in the gastric contractions. The noise level on all completed peak-to-peak analysis was set to zero because an RMS algorithm had already filtered the data. Baseline and maximum drug effect values were taken as a percentage difference using the following formula: $[\{($ maximum - baseline $) /($ baseline $)\} \times 100]$. All percentage data were analyzed for significance of normality using the D'Agostino and Pearson omnibus normality test. A one-sample $t$ test was performed on the data with the hypothetical value set at zero. For ipsilateral vagotomy data, a two-sample paired $t$ test was performed.

To calculate the change in intragastric tone, the maximal or minimal point within a selected timeframe was determined. By comparing the highest or lowest point in the baseline with that of the drug response, an increase or decrease in tone could be determined. All values were taken as a percentage difference, which passed the aforementioned normality tests. A one-sample $t$ test was performed to determine any significance in the control and treatment means.

To calculate the duration of action of MT-II or the $\alpha$-melanocyte stimulating hormone ( $\alpha$-MSH), average peak-to-peak parameters were obtained for a $5 \mathrm{~min}$ baseline period before each drug injection. After the injection, datasets were sampled as continuous $5 \mathrm{~min}$ sets over a $30 \mathrm{~min}$ period, which were later increased to $10 \mathrm{~min}$ segments for an additional 30 min period. [Note that, because MC3-Rs are absent in the dorsal vagal complex (Roselli-Rehfuss et al., 1993; Kistler-Heer et al., 1998; Iqbal et al., 2001), both our in vivo and in vitro data are in reference to the activation of MC4-Rs.]

The change in frequency of gastric phasic contractions was determined by calculating each contraction within a continuous selected timeframe ( 5 min baseline vs $5 \mathrm{~min}$ after microinjection) and analyzed using a paired $t$ test. In all cases, $p<0.05$ was the criterion used to determine statistical significance.

\section{Electrophysiology}

Slices were prepared from brainstems of Sprague Dawley rats ( postnatal days 17-21) or male homozygous $M C 4-R^{-1-}$ mice (4-8 postnatal weeks; The Jackson Laboratory) that had retrograde tracer (DiI) applied to the antrum of their stomach in a manner described previously by us (Sahibzada et al., 2002). Briefly, under isoflurane anesthesia, the brainstem was quickly removed and placed in ice-cold $\left(4^{\circ} \mathrm{C}\right)$ artificial CSF 
(ACSF) solution ( $\mathrm{pH} 7.4$ ) containing the following (in $\mathrm{mm}$ ): $120 \mathrm{NaCl}$, $2.5 \mathrm{KCl}, 26 \mathrm{NaHCO}_{3}, 1.2 \mathrm{NaH}_{2} \mathrm{PO}_{4}, 2 \mathrm{CaCl}_{2}, 1 \mathrm{MgCl}_{2}, 5$ glucose, 10 sucrose, 0.4 ascorbic acid, 3 myo-inositol, and 2 sodium pyruvate. The solution was oxygenated with a carbogen mixture of $95 \% \mathrm{O}_{2}$ and $5 \%$ $\mathrm{CO}_{2}$. Coronal brainstem sections $(250 \mu \mathrm{m})$ containing the NTS and DMV (0.5-1 mm rostral to the CS) were obtained using a vibratome (Vibratome Series 1000) and incubated at $37^{\circ} \mathrm{C}$ for $1 \mathrm{~h}$ in oxygenated ACSF (95\% $\mathrm{O}_{2}$ and 5\% $\mathrm{CO}_{2}$ ) with the following composition (in $\mathrm{mm}$ ): $120 \mathrm{NaCl}, 2.5 \mathrm{KCl}, 26 \mathrm{NaHCO}_{3}, 1.2 \mathrm{NaH}_{2} \mathrm{PO}_{4}, 2 \mathrm{CaCl}_{2}, 1 \mathrm{MgCl}_{2}, 5$ HEPES, and 2.5 glucose, $\mathrm{pH}$ 7.4. The slices were then transferred to a recording chamber (500 $\mu \mathrm{l}$ volume) attached to the stage of a Nikon E600-FN microscope. There, they were continuously perfused at room temperature $\left(21-22^{\circ} \mathrm{C}\right)$ with oxygenated ACSF.

Neurons in the DMV area were identified visually by infrared differential interference contrast or fluorescence optics and a CCD camera (Dage S-75). A $60 \times$ water-immersion objective was used for identifying and approaching neurons.

Cell-attached (loose seal $<40 \mathrm{M} \Omega$ ), whole-cell voltage-clamp $\left(V_{\text {hold }}=\right.$ $-60 \mathrm{mV})$ or current-clamp $\left(V_{\mathrm{m}}=-65 \mathrm{mV}\right)$ recordings of fluorescent DMV antrum-projecting neurons were made with patch electrodes (5-6 $\mathrm{M} \Omega$ ) containing a solution ( $\mathrm{pH}$ 7.2) composed of the following (in $\mathrm{mm}$ ): $145 \mathrm{~K}$-gluconate, 5 EGTA, $5 \mathrm{MgCl}_{2}$, 10 HEPES, 5 ATP.Na, and 0.2 GTP.Na. (Note that action potential firing frequency was not significantly different in parallel cell-attached recordings with ACSF pipette solution.) In studies in which IPSCs were studied, $145 \mathrm{~mm} \mathrm{KCl}$ with $1.7 \mathrm{~mm}$ QX-314 was substituted for potassium gluconate in the pipette solution. The patch pipette was coupled to an amplifier (MultiClamp 700B; Molecular Devices), and its signal was filtered at $2 \mathrm{kHz}$. Series resistance was typically $<10 \mathrm{M}$ and was not compensated but was continuously monitored with a hyperpolarizing $5 \mathrm{mV}$ pulse.

Drug application. Once a stable firing pattern (cell-attached mode) or synaptic currents (voltage-clamp or current-clamp) were recorded, the slice was exposed $(\sim 3-5 \mathrm{~min})$ to MT-II via bath application. This cyclic MSH analog is a full agonist of the MC3/4-Rs (Fan et al., 1997). In some experiments, the slices were exposed to the endogenous melanocortin agonist $\alpha$-MSH. Depending on the experiment, tetrodotoxin (TTX; 1 $\mu \mathrm{M})$, gabazine $(20 \mu \mathrm{M}), \mathrm{CNQX}(10 \mu \mathrm{M})$ or NBQX (5 $\mu \mathrm{M})$, and AP-5 (50 $\mu \mathrm{M})$ were constituted in the ACSF along with the glycinergic antagonist strychnine $(5 \mu \mathrm{M})$. In experiments in which slices were exposed to low calcium $\left(0.2 \mathrm{~mm} \mathrm{CaCl}_{2}\right)$, the ACSF was adjusted for osmolarity by sucrose, which was typically $296 \mathrm{mOsm}$. All drugs were applied via bath application.

Data analyses. Data were analyzed offline using the pClamp 10 software (Molecular Devices). In addition, analysis was also performed using a semi-automated threshold-based software (Mini Analysis; Synaptosoft) and visually confirmed. All data were normalized, and the results are expressed as means \pm SEM. A one-sample $t$ test, a paired $t$ test, or a one-way repeated-measures ANOVA was used to assess significant differences between control and drug-treated conditions. Treatment interactions were assessed by the Tukey's multiple comparisons test. The criterion used to determine statistical significance was $p<0.05$.

\section{Drugs}

The drugs used in both our in vivo and in vitro studies were purchased from the following companies: urethane, $\alpha$-chloralose, L-glutamate, L-NAME, apamin, and kynurenic acid, Sigma-Aldrich; melanotan-II (Ac-Nle-cycloAsp-His-D-Phe-Arg-Trp-Lys-NH2), $\alpha$-MSH (Ac-Ser-Tyr-Ser-Met-GluHis-Phe-Arg-Trp-Gly-Lys-Pro-Val-NH2), and SHU9119 [(2S)-2acetamido- $N$ - [ $(3 S, 6 S, 13 E)-14$ - [ [ $(2 S)-2$ - [ [ (2S)-2-[ [ $(2 R)$-2-amino-3naphthalen-2-ylpropanoyl] amino]-5-(diaminomethylideneamino) pentanoyl] amino]-3-(2,3-dihydro- $1 H$-indol-3-yl)propanoyl] amino]3-(4H-imidazol-4-ylmethyl)-2,5,8,15-tetraoxo-1,4,9-triazacyclopentadec13-en-6-yl]hexanamide], Phoenix Pharmaceuticals; gabazine, CNQX, AP-5, NBQX, CyPPA (cyclohexyl-[2-(3,5-dimethyl-pyrazol-1-yl)-6methyl-pyrimidin-4-yl]-amine), and THIQ ( $N$-[(3R)-1,2,3,4-tetrahydroisoquinolinium-3-ylcarbonyl]-(1R)-1-(4-chlorobenzyl)-2-[4cyclohexyl-4-(1 H-1,2,4-triazol-1ylmethyl)piperidin-1-yl]-2-oxoethylamine), R\&D Systems; TTX, Ascent Scientific. Note that all melanocortin-related peptides used were specifically purchased in single-use aliquots (kept at $-20^{\circ} \mathrm{C}$ ) so that contamination, protein degradation, and concentration errors were avoided.

\section{Experimental design (in vivo)}

Once stable recording of gastric motility was acquired ( $\sim 30 \mathrm{~min})$, L-glutamate ( $500 \mathrm{pmol} / 30 \mathrm{nl} ; 16.7 \mathrm{~mm}$ ) was microinjected into either the DMV or the NTS to determine the nature of gastric responses induced from these nuclei. Invariably, stimulation of the DMV resulted in increases in gastric motility and tone, which was opposite to that elicited from the mNTS. After two stable responses elicited by L-glutamate from either of the two nuclei (interstimulus interval, $\sim 10 \mathrm{~min}$ ), the test compounds or their vehicle were microinjected in animals comprising the following treatment groups.

Microinjection of MT-II in the DMV. These studies $(n=22)$ were undertaken to determine the effect of MT-II on gastric motility at the DMV. Here, as with L-glutamate, two stable responses were obtained (interstimulus interval, $\sim 30 \mathrm{~min}$ ). Because premotor neurons in the DMV project unilaterally via the vagus to the stomach, we used ipsilateral vagotomy (in reference to the side of the injection) to determine the origin of our induced responses. (Note that unilateral vagotomy abolishes responses that are elicited from the DMV, whereas bilateral vagotomy is required to eliminate responses that are of mNTS origin.) After performing ipsilateral vagotomy, a repeat microinjection of MT-II was done. If the MT-II induced before the vagotomy response was abolished, the effect was attributed to that arising from the DMV.

Control microinjection studies in the DMV. These control experiments involved two groups. Group $1(n=3)$ received vehicle injection in the DMV, whereas group $2(n=3)$ received MT-II in areas outside the DMV or NTS.

Microinjection of SHU9119 in the DMV. This group $(n=4)$ initially received MT-II (20 pmol), which was followed $1 \mathrm{~h}$ later by the MC3/MC4 antagonist SHU9119.

Microinjection of MT-II in the DMV and intravenous administration of $L-N A M E$. In these experiments $(n=3)$, MT-II was microinjected into the DMV, and its induced response was subsequently challenged by intravenous administration of L-NAME. This procedure was similar to the ipsilateral vagotomy experiments mentioned above and performed to assess the contribution of a possible nitric oxide pathway.

Microinjection of MT-II and kynurenic acid in the $m N T S$. In addition to the above, the interaction of MT-II and kynurenic acid was studied at the mNTS in one group $(n=4)$. These experiments were performed to determine whether MT-II would unmask the excitatory effect of kynurenic acid in the mNTS as reported previously for the $\mu$-opioid agonist DAMGO (Herman et al., 2010).

Similarly, the above experimental group design was also used for the endogenous melanocortin compound $\alpha$-MSH that was microinjected into the DMV or the mNTS.

\section{Experimental design (in vitro)}

These studies used the following experimental treatment conditions in brainstem slices.

MT-II or $\alpha$-MSH effects on spontaneous action potentials. In these studies, retrogradely labeled DMV antrum-projecting neurons were exposed via bath application to MT-II $(n=24)$ or $\alpha$-MSH $(n=6)$, and their effect was noted on spontaneous action potentials. In another two groups, DMV antrum neurons were preexposed to bath application of SHU9119, followed either by MT-II (group 3, $n=6$ ) or $\alpha$-MSH (group 4, $n=10$ ).

MT-II or $\alpha$-MSH effects on spontaneous action potentials in homozygous in MC4- $R^{-1-}$ mice. In these studies, either MT-II $(n=5)$ or $\alpha-\mathrm{MSH}(n=$ 6) was bath applied to retrogradely labeled DMV neurons from the gastric antrum.

MT-II or $\alpha$-MSH effects on spontaneous action potentials in low $\mathrm{Ca}^{2+}$ $(0.2 \mathrm{~mm})$. In these studies, either MT $(n=5)$ or $\alpha$-MSH $(n=14)$ was bath applied in the presence of low $\mathrm{Ca}^{2+}$ to determine the synaptic site of action.

Underlying mechanism of the action of low $\mathrm{Ca}^{2+}$ on the spontaneous firing frequency of DMV antrum labeled neurons. In these experiments, labeled DMV antrum neurons $(n=7)$ were exposed to the positive SK channel modulator CyPPA in the presence of low-calcium ACSF. 

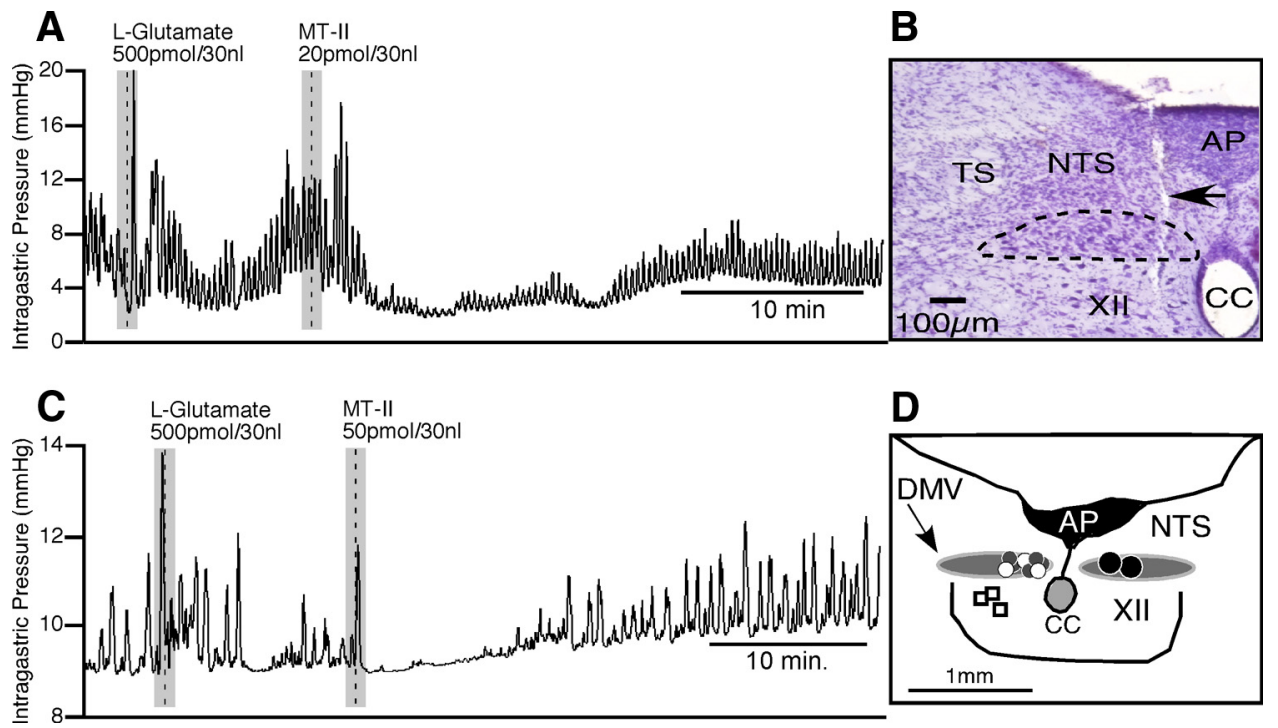

Figure 1. Microinjection of MT-II into the DMV attenuates phasic intragastric activity. $A$, Representative recording showing the effects of L-glutamate and MT-II injections into the DMV on intragastric pressure $(n=12)$. B, Photomicrograph of a representative pipette track (arrow) and its location within the DMV (dashed lines). (Note that the track extends past the DMV, which occurred during initial entrance, but was pulled back up to allow it to reside within the DMV during microinjection of L-glutamate or MT-II). C, A representative tracing showing the effects of a higher dose of MT-II on gastric activity, subsequent to the injection of L-glutamate into the DMV. D, A camera lucida drawing depicting unilateral microinjection sites for saline vehicle (white dots), 50 pmol of MT-II (gray dots; $n=5$ ), and 20 pmol of MT-II (black dots; each dot represents 6 sites; $n=12$ ) into the DMV and 20 pmol of MT-II in the hypoglossal nucleus (open square; $n=3$ ).XII, Hypoglossal nucleus; AP, area postrema; $C$, central canal; TS, solitary tract.

Presynaptic versus postsynaptic effect of MT-II or $\alpha$-MSH on action potentials of labeled DMV antrum neurons. In these experiments, the site of synaptic effect of MT-II $(n=6)$ or $\alpha$-MSH $(n=7)$ on the activity of antrum labeled neurons was assessed in the presence of a mixture of fast synaptic blockers (TTX, CNQX, AP-5, and gabazine).

Effects of MT-II on spontaneous IPSCs and in DMV labeled antrum neurons. In these studies, the effect of MT-II was evaluated on spontaneous IPSCs $(n=16)$ and EPSCs $(n=23)$. In another two groups (group 1, $n=5$; group $2, n=5$ ), these same effects were determined in the presence of TTX.

\section{Results}

\section{Effects of MT-II microinjection into the DMV on gastric} motility and tone

Doses ranging from 2 to 50 pmol of MT-II were microinjected unilaterally into the DMV to determine their effects on gastric motility. When 20 pmol of MT-II was tested $(n=12)$, it produced significant decreases in the amplitude of phasic contractions that averaged $83 \pm 6 \%$ relative to baseline $\left(t_{(11)}=15.45\right.$, $p<0.0001$; Fig. $1 A)$. Gastric tone was not significantly affected ( $6 \pm 4 \%$ decrease from baseline). The effect of MT-II on the frequency of contractions could not be assessed because, in most animals, the amplitude was diminished to such an extent that it was indeterminable. On average, the decrease in the amplitude of phasic contractions occurred at an interval of $2.0 \pm 0.4 \mathrm{~min}$ after MT-II was microinjected and reached a nadir in $4.2 \pm 0.8 \mathrm{~min}$ after microinjection. This attenuation of phasic contraction amplitude never fully wore off; instead, a partial restoration to lower stable amplitude occurred on average $22 \pm 2.2 \mathrm{~min}$ after microinjection. The new steady-state level of amplitude of the contractions was $76 \pm 9 \%$ of the initial magnitude of baseline phasic contractions. Microinjection of MT-II had no significant effect on mean arterial blood pressure.

Although decreases in the amplitude of phasic contractions were the consistent and dominant response, in one-third of the rats $(n=4$ of 12), microinjection of 20 pmol of MT-II evoked an immediate but brief excitatory response (Fig. 1A). The percentage increase in the amplitude of the contraction was $167 \pm 70 \%$, but this was not statistically significant $(p=0.097)$. A representative experiment illustrating the consistent and dominant decrease in the amplitude of phasic contractions in response to microinjection of MT-II appears in Figure $1 A$, as well as the microinjection site for this experiment (Fig. 1B).

To confirm the specificity of our MT-II injections in the DMV and their effect on gastric motility, two types of control experiments were performed. In the first type $(n=3)$, the vehicle for MT-II ( $0.9 \%$ saline) was microinjected unilaterally into the DMV and was found not to have any significant effect on the amplitude of phasic contractions $(14 \pm 13 \%)$. In the second type $(n=3)$, to control for site-specific effects, MT-II (20 pmol) was microinjected unilaterally into sites outside the DMV. In each case, MT-II failed to have any significant effect on the amplitude of phasic contractions of the stomach $(1 \pm 6 \% ; p>0.88)$. The location of these sites, as well as those producing positive MT-II responses, are depicted in the camera lucida drawing shown in Figure $1 D$. As can be noted, the micropipette tip in each case that resulted in an effective MT-II response was located in the medial half of the DMV, specifically, in the portion of the nucleus that runs parallel to the area postrema (Fig. 1D).

In testing a higher dose of MT-II ( $50 \mathrm{pmol}$ ), similar qualitative effects could be observed as that seen with the 20 pmol dose (Fig. 1 , compare $A, C)$. This included the predominate effect of a reduction in the amplitude of phasic contractions $(n=5$; Fig. $1 C)$. The percentage decrease in the amplitude of phasic contractions averaged $67 \pm 16 \%\left(t_{(4)}=4.29, p<0.01\right)$. Although less than the corresponding value for the $20 \mathrm{pmol}$ dose of MT-II, the two values were not statistically different $(p>0.09)$. The effect of MT-II on the frequency of contractions was also assessed and found to be statistically not significant. The decrease in the amplitude of phasic contractions occurred on average $1.2 \pm 0.3 \mathrm{~min}$ after the MT-II was microinjected and reached a nadir in $1.4 \pm$ $0.3 \mathrm{~min}$ after microinjection. The contraction amplitude depression wore off by $14.2 \pm 6.8 \mathrm{~min}$ after microinjection, which at this time was $92 \pm 33 \%$ of the initial magnitude of baseline phasic 
contraction. Microinjection of 50 pmol of MT-II had no significant effect on gastric tone or mean arterial blood pressure. As was the case with the 20 pmol dose of MTII, 50 pmol also produced an initial transient increase in the amplitude of phasic contraction that was marked by a single contraction (Fig. 1C). This occurred in $80 \%$ of the rats tested ( $n=4$ of 5 rats) and was statistically significant relative to baseline $\left(256 \pm 69 \% ; t_{(3)}=3.73, \mathrm{df}=3\right.$; $p<0.03)$.

Because the 50 pmol dose of MT-II did not produce a more intense and longer duration suppression of the amplitude of gastric contractions than the $20 \mathrm{pmol}$ dose of MT-II (Fig. 1 $A, C$ ), a few experiments with lower doses of MT-II (10 pmol, $n=$ 2; 2 pmol, $n=3$ ) were performed. Unilateral microinjection of MT-II at these doses did not significantly affect the amplitude of contractions. Although the initial excitatory effect seen with the higher doses (20 and 50 pmol; Fig. $1 A, C$ ) was also noted for the 10 and 2 pmol doses, when they were examined together as a group, these responses were not statistically significant. The microinjection sites for all the doses of MT-II studied were histologically verified and were found to be located in the DMV. Only the relevant MT-II doses (20 and 50 pmol) are summarized in Figure $1 D$. Incidentally, while determining the effects of MT-II $(20 \mathrm{pmol})$ in the DMV on gastric activity, it was observed that in three animals, microinjections of L-glutamate into the nucleus elicited robust excitatory responses (indicative of DMV activation). However, subsequent MT-II injections at the same site failed to produce any effect on the amplitude of gastric contraction. On histological examination, the microinjection tracks were found to be distributed in the lateral half of the DMV. This was in contrast to experiments in which, subsequent to L-glutamate microinjections, MT-II occasionally produced an initial excitatory response $(n=8$ of 17) that was followed by a consistent robust inhibitory response $(n=17)$ (Fig. $1 A, C)$. In all these experiments, the injection sites were located in the medial half of the DMV. This finding emphasizes the importance of locating the pipette tip in the medial portion of the DMV to obtain a response with this drug.

Because the 20 pmol dose of MT-II at the DMV produced an optimal response in terms of inhibition of the amplitude of gastric contractions, we chose this dose of MT-II to further characterize its effect at the DMV. This focused on three issues. The first was to determine whether it was restricted to the DMV neurons or whether neurons in the nearby mNTS were also involved. The second was to confirm that the MT-II-induced gastric response was attributable to activity at the MC4-Rs. The third concerned the type of efferent DMV pathway that was involved in mediating the MT-II inhibitory response on gastric contractility. Currently, it is thought by several investigators that gastric inhibitory responses mediated by DMV neurons is attributable to both inhibition of an excitatory cholinergic-cholinergic pathway and activation of an inhibitory cholinergic-nitric oxide pathway (Rogers et al., 2003; Hermann et al., 2006; Travagli et al., 2006; Zhou et al., 2008). To study these issues, we first had to confirm whether the inhibitory responses displayed with 20 pmol of MT-II were repeatable in the same animal, thereby enabling us to test interventions such as ipsilateral vagotomy [a test of a DMV-evoked response (Ferreira et al., 2002; Cruz et al., 2007)] or microinjection of SHU9119 (an antagonist selective for the MC3/4-Rs) into the DMV or intravenous administration of L-NAME (a test to determine the role of nitric-oxide-containing neurons). MT-II was microinjected twice into the DMV at a $1 \mathrm{~h}$ interval $(n=3)$. Both injections inhibited gastric contractility; the magnitude of the decreases was not significantly different (first injection, $70 \pm 5 \%$; second, $79 \pm 12 \%$; $p=0.34$ ). The recovery to steady state was achieved within $30 \mathrm{~min}$ after each injection of MTII. Consequently, this time interval was chosen between MT-II microinjections in later experiments to allow us to test interventions that included ipsilateral vagotomy, microinjection of SHU9119, and administration of L-NAME (intravenously).

To test for the involvement of the mNTS in the MT-IIinduced response, a half-hour after the first MT-II microinjection, the ipsilateral cervical vagus nerve was sectioned and a second MT-II microinjection was made. In each case, ipsilateral cervical vagotomy abolished the MT-II-induced decrease in the amplitude of phasic contractions (initial MT-II response, $81 \pm$ $6 \% ; t_{(3)}=13.81, p<0.001$; after vagotomy, $10 \pm 9 \% ; p=0.31 ;$ $n=4)$. In addition, ipsilateral vagotomy also abolished the L-glutamate increase in gastric motility $(n=4)$, thus confirming that our microinjections were localized to the DMV. (Note that the ipsilateral vagotomy in itself did not significantly affect gastric motility or tone.)

To determine whether the 20 pmol MT-II response was attributable to its activation of MC4-Rs, the antagonist SHU9119 was used. MT-II ( 20 pmol; $n=4)$ microinjected into the DMV significantly depressed gastric phasic contraction amplitude (82 \pm $9 \% ; t_{(3)}=6.71, p<0.03$; Fig. $2 A$, left $)$. After $1 \mathrm{~h}$, SHU9119 (50 pmol) was microinjected into the DMV; this was followed $15 \mathrm{~min}$ later by a repeat MT-II injection. MT-II failed to produce any significant change in the amplitude of phasic contraction $(4 \pm$ 6\%; Fig. 2A, right). After $4 \mathrm{~h}$ post-microinjection of SHU9119, the ability of MT-II to depress gastric phasic contraction ampli- 
tude was never restored. In addition, when SHU9119 was microinjected in three of the four animals, it increased gastric tone $\left(0.65 \pm 0.05 \mathrm{mmHg} ; t_{(2)}=3.16, p<0.01\right)$ but had no significant effect on the amplitude of gastric phasic contractions. Histological verification in three of the four experiments showed the pipette placement to be in the DMV; the other was located in the mNTS (Fig. 2A, inset).

To address the type of efferent DMV pathway that was activated by MT-II in the DMV, L-NAME was tested in the same way that ipsilateral cervical vagotomy was tested. Initially, MT-II (20 pmol; $n=3$ ) microinjected into the DMV evoked its characteristic response. A half-hour later, L-NAME (10 mg/kg, i.v.) was administered, which was followed $5 \mathrm{~min}$ later by a repeat microinjection of MT-II. L-NAME treatment failed to inhibit MT-IIinduced depression of phasic contractions (before L-NAME, $78 \pm 11 \%$; after L-NAME, $80 \pm 12 \%$ ). The effects of L-NAME per se did not significantly alter the amplitude of gastric phasic contractions but did significantly increase gastric tone $(4.1 \pm 0.8$ mmHg; $\left.t_{(4)}=5.1, p<0.001\right)$. Histological verification of the microinjection sites in the three experiments showed the pipette placement to be in the medial portion of the DMV (data not shown).

\section{Effects of $\alpha$-MSH microinjection into the DMV on gastric motility and tone}

These studies were undertaken to compare the effects of the endogenous melanocortin receptor agonist $\alpha$-MSH on gastric contractility with those of MT-II. We used a fivefold higher dose of $\alpha$-MSH $(100 \mathrm{pmol})$ to MT-II because of its lesser potency $\left(\mathrm{IC}_{50}=\right.$ $\left.19 \mathrm{nM} ; \mathrm{EC}_{50}=1.6 \mathrm{nM}\right)$ compared with MT-II $\left(\mathrm{IC}_{50}=0.07 \mathrm{nM}\right.$; $\mathrm{EC}_{50}=0.45 \mathrm{~nm}$ ) (MacNeil et al., 2002) and our own studies, which revealed the optimal dose of MT-II at the DMV to be 20 pmol.

Unilateral microinjection of $\alpha$-MSH (100 pmol) into the DMV caused a significant increase in the amplitude of phasic contractions $\left(126 \pm 34 \% ; t_{(5)}=3.69, p<0.02 ; n=6\right.$; Fig. $2 B$, left). On average, the time to onset of these contractions was $5 \pm$ $7 \mathrm{~s}$, and their peak effect occurred at $30 \pm 13 \mathrm{~s}$ after microinjection. The duration of action was short $(1.9 \pm 0.5 \mathrm{~min})$ and recovered to a steady state that did not differ significantly from baseline. In contrast to MT-II, this excitatory response was the dominant gastric response elicited from the DMV without any accompanying depression in gastric activity (Fig. $2 B$, left). No significant changes in gastric tone $(+0.52 \pm 0.20 \mathrm{mmHg})$, mean arterial pressure $(-2.5 \pm 1.6 \mathrm{mmHg})$, or phasic contractile frequency $(+0.04 \pm 0.02 \mathrm{~Hz})$ were noted. Microinjection of $\alpha$-MSH was repeatable at $30 \mathrm{~min}$ intervals without any significant difference between the first and second microinjection of $\alpha$-MSH $(94 \pm 10$ and $108 \pm 5 \%$, respectively). To determine the optimal dose of $\alpha$-MSH, lower doses of it were used $(1,10$, and 20 pmol; $n=1$ per dose) at the DMV. These had lesser effects on the percentage change in the amplitude of contractions than the 100 pmol dose ( 1 pmol, 7\%; 10 pmol, 24\%; 20 pmol, 13\%). No effects on gastric tone, frequency of contraction, or mean arterial blood pressure were noted at these doses. Based on these observations, the 100 pmol dose of $\alpha$-MSH was deemed optimal and was further used to characterize the actions of $\alpha-\mathrm{MSH}$ at the DMV. Histological verification of the microinjection site for the experiment shown as Figure $2 B$ appears in the inset. It shows the pipette placement to be in the medial portion of the DMV. This was also the case for the other five experiments in this study (data not shown).

In characterizing the effect of $\alpha-\mathrm{MSH}$ at the DMV on gastric activity, similar protocols to those of MT-II were used. Unilateral injections of $\alpha$-MSH in the DMV significantly increased the percentage change in the amplitude of contractions by $96 \pm 19 \%$ $\left(t_{(4)}=5.1, p<0.007 ; n=6\right)$ compared with baseline. This response was blocked by ipsilateral vagotomy $\left(13 \pm 13 \% ; t_{(8)}=\right.$ $4.8, p<0.001 ; n=6$; Fig. $2 B$, right).

Although, both $\alpha$-MSH and MT-II are reported to be agonists at MC3/MC4-Rs, they had opposite functional effects on the stomach. To confirm that this was not attributable to acrossgroup variation, a set of experiments was performed $(n=3)$ in which $\alpha$-MSH ( $100 \mathrm{pmol}$ ) was unilaterally microinjected into the DMV and followed 30 min later by MT-II (20 pmol). The rationale in these experiments for the order of the drugs microinjected was that $\alpha$-MSH shows an excitatory short-acting response with full recovery, whereas MT-II shows an inhibitory longerduration response without a full recovery. Using the above protocol, microinjection of $\alpha$-MSH increased the percentage average amplitude of phasic contractions $\left(558 \pm 21 \%\right.$; $t_{(2)}=26.57, p<$ 0.001 ; Fig. $3 A$, left) compared with MT-II, which decreased it $\left(87 \pm 7 \% ; t_{(2)}=12.43, p<0.006\right.$; Fig. $3 A$, right $)$. Verification of the sites of microinjection of the drugs is shown in the camera lucida drawing (Fig. 3, inset).

To confirm that $\alpha$-MSH-induced increase in the amplitude of phasic gastric contractions was mediated through MC4-Rs, SHU9119 (50 pmol) was microinjected into the DMV $(n=3)$, which was preceded by an initial injection of $\alpha$-MSH (100 pmol) and followed by a second injection of the same drug. Microinjection of $\alpha$-MSH produced an increase in phasic amplitude (142 \pm $27 \%$; $t_{(2)}=5.34, p<0.033$; Fig. $3 B$, left) that was blocked by SHU9119 ( $\pm 3 \%$; $\left.t_{(2)}=5.01, p<0.037\right)$ when $\alpha$-MSH was subsequently repeated (Fig. $3 B$, right). There was no significant effect of SHU9119 on gastric activity (phasic amplitude, $7 \pm 30 \%$; gastric tone, $+0.18 \pm 0.16 \mathrm{mmHg}$ in reference to baseline). Histological verification of all pipette tracks confirmed that they were located within the DMV (Fig. 3, inset). The attenuation of $\alpha$-MSH elicited gastric responses by SHU9119 never recovered over the duration of the experiment $(\sim 4 \mathrm{~h})$.

Melanocortin receptors other than MC4-R have not been reported to be present in the NTS or DMV (see Materials and Methods). Nevertheless, we injected the selective MC4 agonist THIQ into the DMV to determine whether its effect on gastric motility resembled MT-II or $\alpha$-MSH. Similar to $\alpha$-MSH, THIQ (30 pmol; $n=3$ ) excited gastric motility ( $115 \pm 7 \%$ increase from baseline; Fig. $3 C$, left) that was blocked by ipsilateral vagotomy (Fig. 3C, right).

\section{Effects of MT-II microinjection into the mNTS on gastric motility and tone}

Based on the information we accumulated using 20 pmol of MT-II at the DMV, we used this dose to study its effects at the mNTS. Unilateral microinjection of MT-II produced a significant decrease in the amplitude of phasic contractions $(83 \pm 6 \%$; $n=7 ; t_{(6)}=14.06, p<0.0001$; Fig. $4 A$ ). Gastric tone was not significantly affected $(3.0 \pm 2 \%)$. The effect of MT-II on the frequency of contractions could not be assessed because, in most animals, the amplitude of contraction diminished to such an extent that frequency could not be measured. The decreases in the amplitude of phasic contractions occurred on average $30 \pm 3.5 \mathrm{~s}$ after MT-II was microinjected and reached a nadir in $1.1 \pm 0.6$ min after microinjection. The decrease in phasic contractions did wear off, and restoration to baseline occurred $12 \pm 3.9 \mathrm{~min}$ after MT-II was microinjected. Microinjection of MT-II had no significant effect on mean arterial blood pressure. In five of the seven rats tested, microinjection of $20 \mathrm{pmol}$ of MT-II evoked an imme- 
diate but brief excitatory response, consisting of a single large-amplitude contraction (Fig. 4A). The percentage increase in the amplitude of the contraction was $448 \pm 175 \%$, but this value did not achieve statistical significance.

To control for vehicle effects, the MT-II vehicle, saline, was microinjected unilaterally into the mNTS $(n=3)$ and was found to have no significant effect on the amplitude of phasic contractions. The microinjection sites for 20 pmol of MT-II and saline vehicle were histologically verified, and pipette tip placements for the mNTS are summarized in the camera lucida drawing in Figure 4C. As can be noted, the micropipette tip in each case was located in the mNTS, specifically in the portion of the nucleus that runs parallel to the area postrema.

To confirm that our responses obtained with MT-II microinjection into the mNTS were in fact from it and not from the nearby DMV (Fig. 1), studies were performed to determine whether its effects were repeatable and whether ipsilateral vagotomy would prevent the response elicited by MT-II as it does when it is microinjected into the DMV. In five experiments, two MT-II microinjections given 30 min apart attenuated gastric contractility to a degree that was not significantly different from each other (first response, $85 \pm 7 \%$; second response, $83 \pm 9 \%$; $n=$ $5)$, thus establishing its repeatability of MT-II in the mNTS. To evaluate the effect of ipsilateral vagotomy $(n=7)$, a halfhour after the first MT-II microinjection was given, the ipsilateral vagus was avulsed and the MT-II microinjection was repeated $10 \mathrm{~min}$ later. In each case, ipsilateral vagotomy had no effect on the MT-II-induced decrease in amplitude of phasic contractions (before vagotomy, $83 \pm 6 \%$; after vagotomy, $79 \pm 4 \% ; p=0.91)$. With subsequent bilateral vagotomy, MT-II had no significant effect on the amplitude of contraction $(3 \pm 2 \%$; $p>$ 0.05 ), indicating that the pre-bilateral vagotomy responses were of mNTS origin.

\section{Effects of $\alpha$-MSH microinjection into the mNTS on gastric motility and tone}

Similar to MT-II, $\alpha$-MSH was injected into the mNTS to characterize its effect on gastric activity. Unilateral microinjection of $\alpha$-MSH ( $100 \mathrm{pmol})$ into the mNTS $(n=5)$ resulted in an immediate (time to onset, $12 \pm 5 \mathrm{~s}$ ) attenuation of gastric phasic contractions $\left(71 \pm 3 \% ; t_{(4)}=20.66, p<0.0001\right.$; Fig. $\left.4 B\right)$ that was accompanied by a significant drop in gastric tone $(0.64 \pm 0.13$ mmHg; $t_{(4)}=4.98, p<0.005$; Fig. $\left.4 B\right)$ and a reduction in mean arterial blood pressure $\left(15 \pm 2.6 \mathrm{mmHg}_{(4)}=5.77, p<0.003\right)$. The frequency of phasic contractions could not be assessed because of their diminished amplitude. The duration of action of $\alpha$-MSH in the mNTS on gastric activity was $4.6 \pm 0.6 \mathrm{~min}$, after
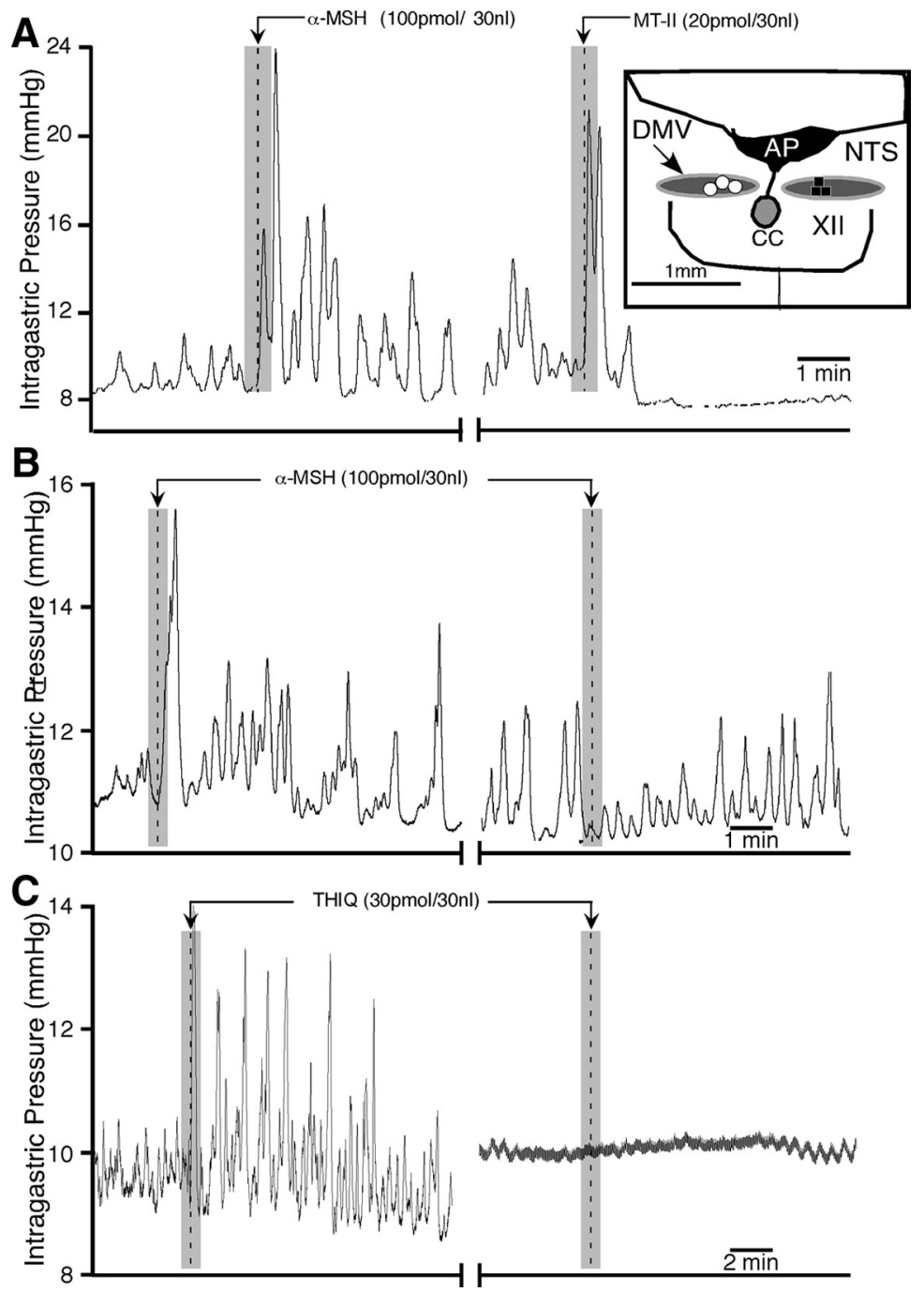

Figure 3. Comparative effects of $\alpha$-MSH, MT-II, and THIQ on gastric motility in the DMV. $\boldsymbol{A}$, Representative experimental t in $\boldsymbol{A}$ is a camera lucida drawing that shows the distribution of unilateral microinjection sites for $\alpha$-MSH followed by MT-II 作 right) given at the same site (injection marker not shown). C, A representative experimental tracing showing gastric response induced by microinjection of the selective MC4-R agonist THIQ in the DMV, which is blocked by ipsilateral vagotomy $(n=3)$. XII, Hypoglossal nucleus; AP, area postrema; CC, central canal.

which baseline levels were fully restored. Unlike MT-II, microinjections of $\alpha$-MSH in the mNTS produced only a depression in gastric activity and did not show an initial transient excitatory response. Repeated injections of $\alpha-\mathrm{MSH}$ at $30 \mathrm{~min}$ intervals did not reveal any statistical difference between the initial inhibitory response $(78 \pm 5 \%)$ and the subsequent one $(81 \pm 8 \%)$. To isolate the influence of the nearby DMV from that of the mNTS, ipsilateral vagotomy was performed in all animals tested above $(n=5)$. Microinjection of $\alpha$-MSH into the mNTS before ipsilateral vagotomy induced an inhibitory response $\left(71 \pm 3 \% ; t_{(4)}=6.28, p<0.004\right)$ that was not significantly altered after sectioning the cervical vagus $(65 \pm 10 \%)$.

Similar to the experimental protocol used for the DMV (Fig. 2 ), microinjection of SHU9119 (50 pmol) into the mNTS $(n=3)$ attenuated subsequent responses of $\alpha$-MSH from its initial amplitude values of phasic contraction ( $82 \pm 7$ compared with $5 \pm 6 \%$; $t_{(4)}=8.17, p<0.002$; Fig. 5$)$ and gastric tone $(0.71 \pm 0.14 \mathrm{mmHg}$ 

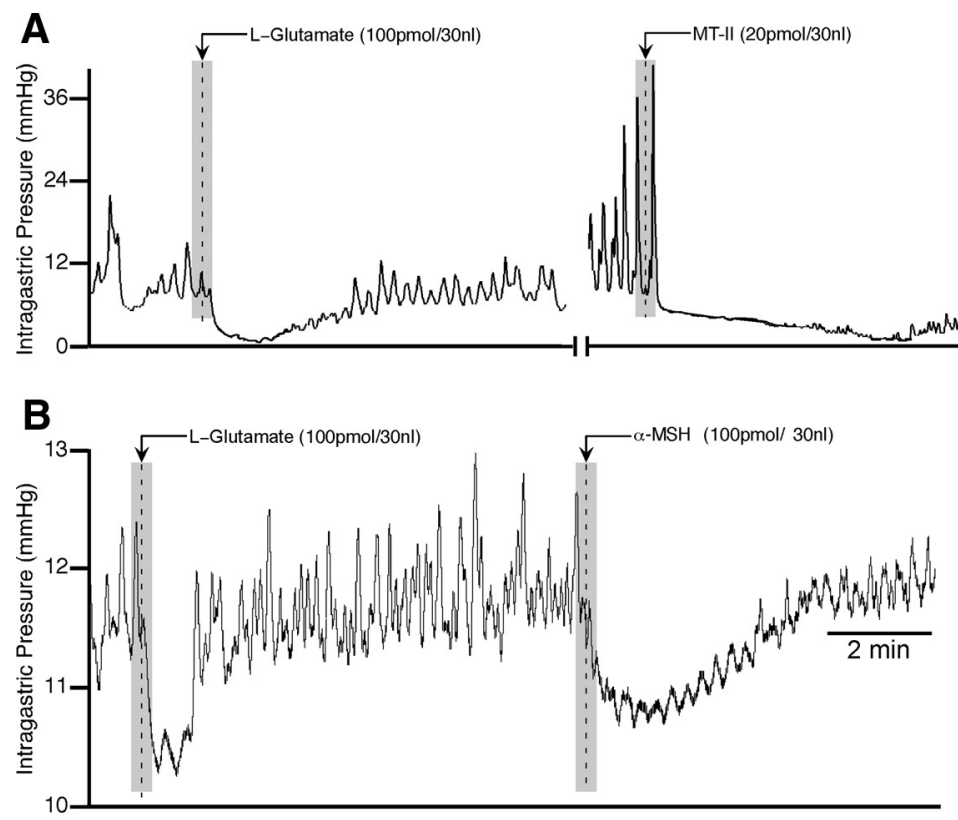

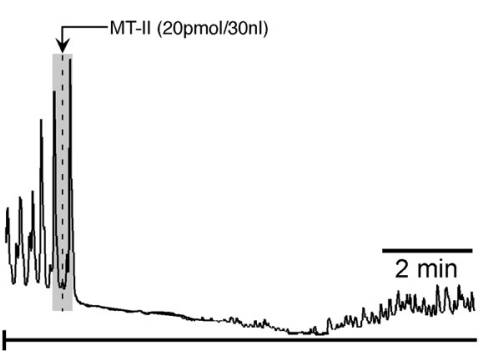

C

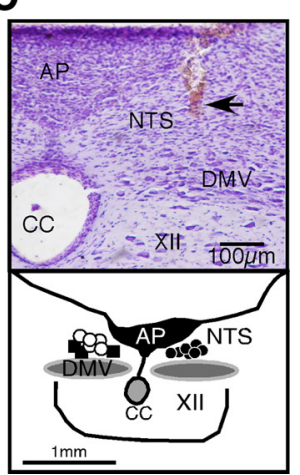

Figure 4. Effects of microinjections of melanocortin receptor agonists into the mNTS on gastric activity. Representative tracings illustrating the effects of microinjections of $\mathrm{L}-\mathrm{glutamate}(\boldsymbol{A}, \boldsymbol{B})$, MT-II (A), and $\alpha$-MSH $(\boldsymbol{B})$ into the mNTS after ipsilateral vagotomy. $\boldsymbol{C}$, Representative photomicrograph of a pipette track (top) whose tip location (arrow) resides in the mNTS. Similar tip locations are depicted in the camera lucida drawing (bottom) for unilateral microinjection sites in the mNTS for 20 pmol of MT-II (black dots; $n=7$ ), 100 pmol of $\alpha$-MSH (white dots; $n=5$ ), and saline vehicle (black squares; $n=3$ ). XII, Hypoglossal nucleus; AP, area postrema; $C$, central canal.

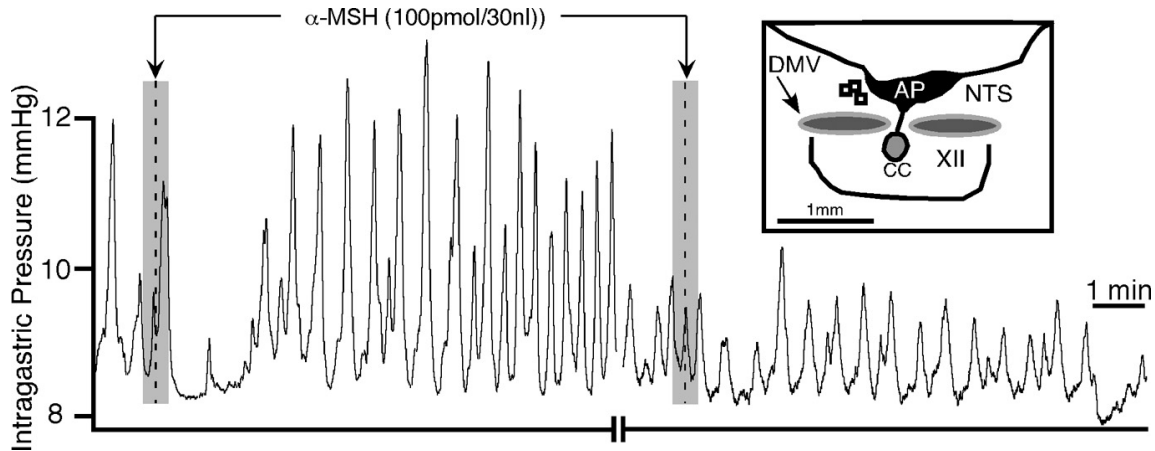

Figure 5. $\quad \alpha$-MSH-induced gastric response from the $\mathrm{mNTS}$ is blocked by SHU9119 $(50 \mathrm{pmol} ; n=3)$ given at the same site (injection marker not shown). Inset is a camera lucida drawing showing the unilateral microinjection sites for SHU9119 followed by $\alpha$-MSH (open squares) in the NTS. XII, Hypoglossal nucleus; AP, area postrema; CC, central canal.

observed with DAMGO (Herman et al., 2009). In addition, DAMGO unmasked an excitatory effect of kynurenic acid at the mNTS. Hence, to further characterize $\alpha$-MSH at this nucleus, we assessed whether this agent would also unmask an excitatory effect of kynurenic acid. Five experiments were performed wherein $\alpha$-MSH $(100 \mathrm{pmol})$ was microinjected into the mNTS and allowed to evoke its typical effects (Fig. 6A). Five minutes later, kynurenic acid ( $1 \mathrm{nmol}$ ) was microinjected into the same site, followed $1 \mathrm{~min}$ later by a repeat microinjection of $\alpha$-MSH. Kynurenic acid, which normally has no effect (Herman et al., 2009), evoked large increases in amplitude of gastric contractions $(371 \pm 102 \% ; n=5$,

compared with $\left.0.04 \pm 0.10 \mathrm{mmHg} ; t_{(4)}=3.89, p<0.02\right)$. However, the decrease in mean arterial pressure elicited by $\alpha$-MSH was not significantly altered (17.8 \pm 9.8 compared with $12.2 \pm$ $6.8 \mathrm{mmHg}$ ). Similar to the DMV, SHU9119 suppression of $\alpha$-MSH-mediated gastric effects at the mNTS did not recover for the extent of the experiment $(\sim 4 \mathrm{~h})$. SHU9119 alone did not significantly affect phasic amplitude or gastric tone during microinjection in the mNTS $(+80 \pm 141 \%$ and $+0.31 \pm 0.47$ $\mathrm{mmHg}$, respectively).

In summary, as is the case of differences in responses of $\alpha$-MSH and MT-II elicited from the DMV, responses elicited by these two substances from the mNTS also differed. In contrast to MT-II, $\alpha$-MSH produced decreases in gastric tone and blood pressure that was not preceded by an initial excitatory effect on the amplitude of gastric motility. The two substances did both decrease the amplitude of contractions. The constellation of effects observed with $\alpha$-MSH, but not with MT-II, resembled those $\left.t_{(4)}=3.64, p<0.03\right)$ and gastric tone $[1.5 \pm 0.4 \mathrm{mmHg} ; n=5$; $t_{(4)}=3.75, p<0.02$ (Fig. 6B)]. The effects of kynurenic acid took $\sim 7.4 \pm 1.6 \mathrm{~min}$ to occur. Histological verification in five experiments showed the pipette placement to be in the mNTS (Fig. $6 C$ ). Figure $6 D$, top, shows bar graphs summarizing the effect of $\alpha$-MSH on phasic amplitude of contractions and blood pressure before and after microinjection of kynurenic acid. Figure $6 D$, bottom, shows bar graphs summarizing the effect of kynurenic acid alone and during $\alpha$-MSH application on phasic amplitude of contractions, tone, and frequency of contractions.

Similar experiments were performed with MT-II (20 pmol; $n=4)$ and kynurenic acid $(1 \mathrm{nmol})$. In contrast to the robust interaction seen between $\alpha$-MSH and kynurenic acid, MT-II did not unmask any excitatory response of kynurenic acid from the mNTS. 
Effects of MC3/4 agonists on spontaneous action potentials recorded in vitro from DMV antrum-projecting neurons

Our in vivo data indicate that the two MC3/4-R agonists MT-II and $\alpha$-MSH exert opposite effects on amplitude of phasic gastric contractions when microinjected into the DMV. The predominate effect of MT-II is inhibitory, whereas that of $\alpha-\mathrm{MSH}$ is excitatory. In seeking an explanation for these opposing effects, we used a reduced preparation, namely, the brain slice containing the part of the DMV that we found responsive to both drugs. Because phasic gastric activity originates in the corpus and culminates in the antropyloric region (el-Sharkawy et al., 1978), we focused on recording from retrogradely labeled antrum neurons.

The effects of the MT-II and $\alpha$-MSH on spontaneous action potentials were studied in retrogradely labeled antrum neurons in the cell-attached mode (loose seal $<40 \mathrm{M} \Omega$ ). Bath application of MT-II (100 nM) for 3-5 min significantly attenuated the mean neuronal firing rate from baseline by $42 \pm 4 \%\left(t_{(23)}=9.81, p<\right.$ 0.0001 ; Fig. $7 A)$ in a reversible manner $(n=24)$. Similarly, bath application of $\alpha$-MSH (500 nM) significantly suppressed the average neuronal firing rate by $44 \pm$ $9 \%\left(t_{(5)}=4.49, p<0.006\right.$; Fig. $\left.7 A\right)$ in DMV antrum-projecting neurons $(n=$ 6). A representative experiment demonstrating this decrease in firing rate appears as Figure $7 B$. In another set of experiments, the percentage decrease in neuronal firing seen after exposure to the $\mathrm{MC} 3 / 4$ agonists was tested in neurons that were preexposed to bath application of SHU9119 (500 nM). In all neurons recorded, MT-II (100 nM; $n=6$ ) or $\alpha$-MSH ( $500 \mathrm{nM} ; n=10)$ failed to significantly inhibit action potential firing after a $5 \mathrm{~min}$ bath application ( $8 \pm 9$ and $11 \pm 10 \%$, respectively; Fig. $7 A)$.

As mentioned above, melanocortin receptors other than MC4-R have not been reported to be present in the NTS or the DMV. To confirm this, we recorded from DMV labeled antrumprojecting neurons in $M C 4-R^{-/-}$mice. Exposure to either MT-II $(n=5)$ or $\alpha$-MSH $(n=5)$ did not significantly affect the neural firing of these neurons.

To determine whether the inhibition of action potentials seen with the MC3/4 agonists were presynaptic in origin, the effects of both MT-II and $\alpha$-MSH were studied in the presence of low calcium $\left(0.2 \mathrm{~mm} \mathrm{CaCl}_{2}\right)$. A one-way repeated-measures ANOVA and Tukey's post hoc comparisons was used to test for differences among treatment conditions. In the five neurons studied, bath application of low-calcium ACSF (5-10 min) dramatically increased the mean neuronal firing rate from baseline by $3.1 \pm 0.4$ $\mathrm{Hz}(p<0.01)$, an increase of $94 \%$ (Fig. 7C). This increase from baseline activity was significantly reduced by application of MT-II (100 nM) in the presence of low calcium by $1.7 \pm 0.4 \mathrm{~Hz}$ $(p<0.05$; Fig. $7 C)$, a decrease of $35 \%$. In a separate set of DMV antrum-projecting neurons $(n=14)$, low-calcium ACSF application (5-10 $\mathrm{min}$ ) increased the mean frequency of action potentials from baseline by $4.2 \pm 0.7 \mathrm{~Hz}(p<0.0001)$, an increase of
C
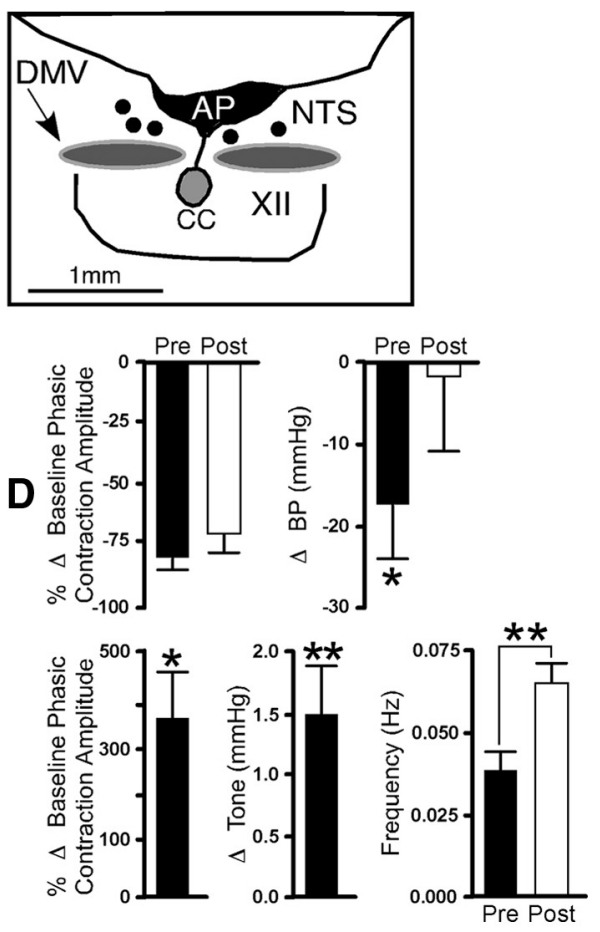

$2 \min$

Figure 6. Microinjection of kynurenic acid into the mNTS in the presence of $\alpha$-MSH increases gastric phasic activity and tone. $\boldsymbol{A}$ bottom graphs illustrate the effect of kynurenic acid alone after $\alpha$-MSH on phasic contractions (left), tone (middle), and frequency of contractions (right). XII, Hypoglossal nucleus; AP, area postrema; CC, central canal. ${ }^{*} p<0.03$; ${ }^{* *} p<0.02$.

$400 \%$, which was further significantly increased on exposure to $\alpha$-MSH (500 nM) by $0.7 \pm 0.2 \mathrm{~Hz}(p<0.05$; Fig. $7 D)$, an increase of $13 \%$. A representative recording from an antrum labeled neuron (see photomicrograph) showing an increase in neuronal firing rate with $\alpha-\mathrm{MSH}$ in low calcium is presented in Figure $7 E$. The decrease in neuronal firing rate with MT-II and its increase with $\alpha$-MSH in low calcium indicate postsynaptic effects of the two substances. It is noteworthy that these two substances have contrasting postsynaptic effects on DMV neurons.

The spontaneous firing frequency of DMV neurons is modulated primarily by small-conductance $\mathrm{Ca}^{2+}$-dependent $\mathrm{K}^{+}$channels (SK) (Pedarzani et al., 2000). Inhibition of these channels by apamin increases the firing frequency of neurons (Pedarzani et al., 2000). To determine whether the increase in neuronal activity induced by lowcalcium ACSF was attributable to decrease in SK channel activity, neurons $(n=7)$ were exposed to its positive modulator, CyPPA ( 10 $\mu \mathrm{M} ; 5 \mathrm{~min})$. In the presence of low-calcium ACSF, bath application of the SK modulator significantly reduced the mean neuronal activity by $0.7 \pm 0.2 \mathrm{~Hz}(p<0.05)$, a decrease of $51 \%$. Before this, low-calcium ACSF alone had increased the mean activity from baseline by $0.9 \pm 0.2 \mathrm{~Hz}(p<0.05$; Fig. $7 F)$.

The postsynaptic effect of both MT-II $(n=6)$ and $\alpha$-MSH $(n=7)$ on DMV antrum-projecting neurons was also studied in the presence of a mixture of fast synaptic blockers (TTX, 1 $\mu \mathrm{M}$; CNQX, $10 \mu \mathrm{M}$; AP-5, $50 \mu \mathrm{M}$; gabazine, $10 \mu \mathrm{M}$ ). Whereas MT-II did not significantly affect the membrane potential, $\alpha$-MSH depolarized the membrane $\left(t_{(6)}=4.370, p<0.0024\right.$; Fig. 7G). 
A
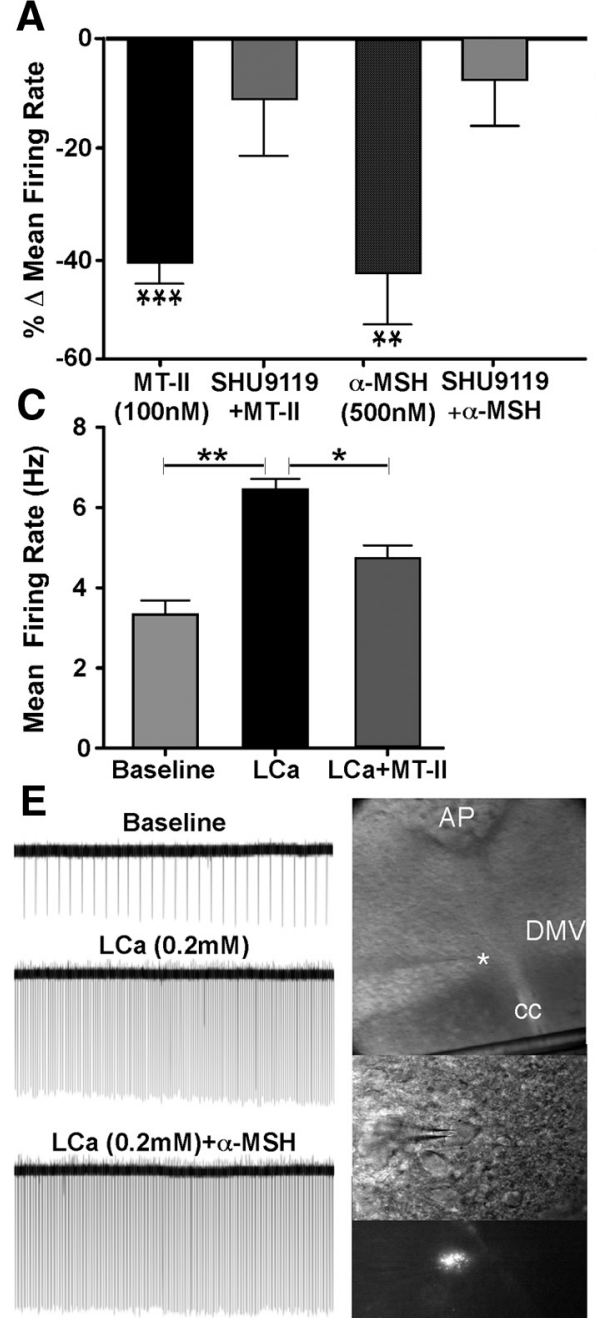

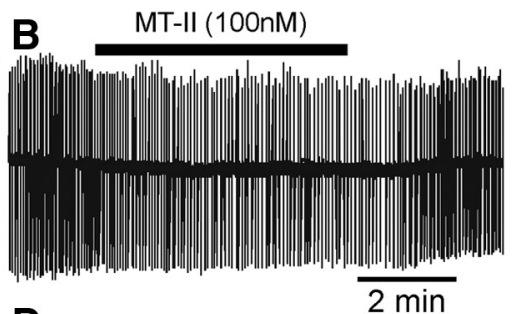

D

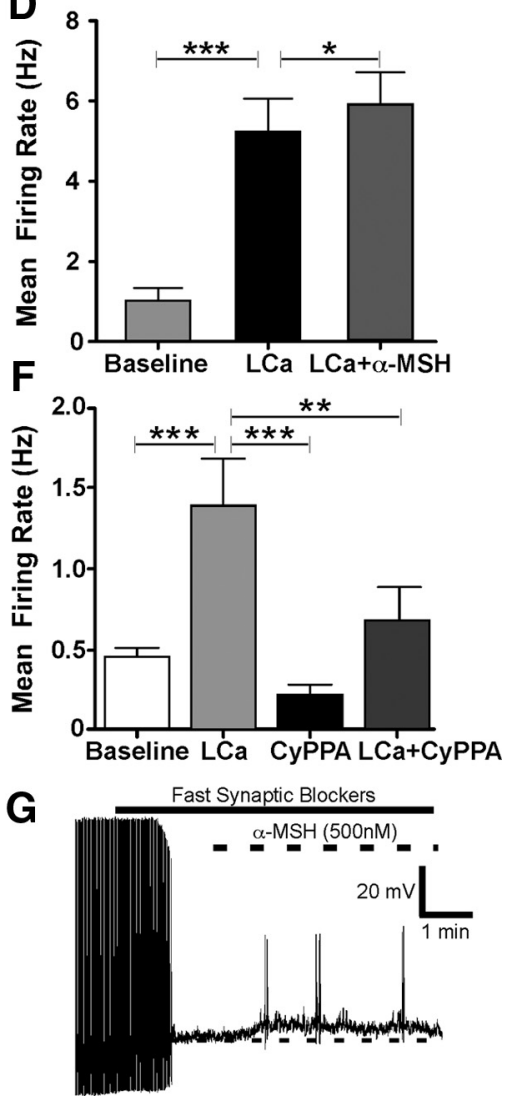

Figure 7. The MC4-R agonists MT-II and $\alpha$-MSH attenuate neuronal activity in antrum-projecting DMV neurons. $\boldsymbol{A}$, Summary graph showing the mean percentage change in firing rate from baseline of DMV neurons subsequent to bath application of MT-II ( $n=6$ ) or $\alpha$-MSH $(n=10)$, which is significantly attenuated by concurrent application of the melanocortin antagonist SHU9119 $(100 \mathrm{~nm}) . \boldsymbol{B}$, A representative loose cell-attached recording showing the effect of bath application of MT-II on the firing rate of a neuron labeled from the gastric antrum. $\boldsymbol{C}, \boldsymbol{D}$, Graphs showing the effect of MT-II $(\boldsymbol{C} ; n=5)$ and $\alpha$-MSH $(\boldsymbol{D} ; n=14)$ on DMV neurons in the presence of low-calcium (LCa;0.2 mM) ACSF. $\boldsymbol{E}$, Loose cell-attached recording from a labeled antrum-projecting DMV neuron (in photomontage on right) exposed to $\alpha$-MSH in the presence of low-calcium ACSF. (Note that $\alpha$-MSH further increases the frequency of action potential firing subsequent to low-calcium ACSF exposure. The star in the photomontage denotes the location of the recording pipette from where the labeled DMV neuron seen in the lower images was recorded.) $\boldsymbol{F}$, Graph showing the effect on neuronal activity of bath application of low-calcium (LCa) ACSF alone ( $n=7)$ and in the presence of the SK-positive channel modulator CyPPA (10 $\mu \mathrm{M})$. G, Current-clamp recording from a labeled DMV neuron illustrating the effect of $\alpha$-MSH on membrane potential $(n=7)$ in the presence of TTX ( $1 \mu \mathrm{m})$ and fast synaptic blockers (CNQX, $10 \mu \mathrm{m} ; \mathrm{AP}-5,50 \mu \mathrm{m} ;$ gabazine, 10 $\mu \mathrm{M})$. AP, Area postrema; CC, central canal. * $p<0.05$; ${ }^{* *} p<0.01$; ${ }^{* *} p<0.0001$.

\section{Effects of MC3/4 agonists on spontaneous IPSCs and EPSCs} in DMV neurons that project to the antrum of the stomach In whole-cell voltage-clamp mode, recordings were made from 16 retrogradely labeled DMV antrum-projecting neurons. Exposure to MT-II $(100 \mathrm{nM})$ via bath application significantly enhanced the frequency of spontaneous IPSCs (Fig. 8A) from a baseline of $4.6 \pm$ 0.8 to $9.03 \pm 1.3 \mathrm{~Hz}\left(t_{(15)}=5.77, p<0.0001 ;\right.$ Fig. $\left.8 B\right)$, an increase of $96 \%$. In addition to frequency, bath application of MT-II also significantly increased the amplitude of IPSCs in the DMV neurons from a mean baseline of $50.2 \pm 12.8 \mathrm{pA}$ to that of $67.1 \pm 15.1 \mathrm{pA}\left(t_{(15)}=\right.$ $5.1, p<0.01$; Fig. $8 C$ ), an increase of $34 \%$. Bath application of the $\mathrm{GABA}_{\mathrm{A}}$ antagonist gabazine $(10 \mu \mathrm{M})$ inhibited the occurrence of
IPSCs in all neurons that were exposed to the drug. In five separate neurons, preexposure to TTX $(1 \mu \mathrm{M})$ blocked the ability of MT-II to enhance IPSC frequency.

The effect of $\alpha-\mathrm{MSH}$ on IPSCs was tested in five neurons. Similar to MT-II, bath application of $\alpha$-MSH (500 nM) significantly increased the IPSC frequency from a baseline of $1.5 \pm 0.2$ to that of $3.2 \pm 0.6\left(t_{(4)}=3.67, p<0.05\right)$, an increase of $119 \%$; however, the amplitude of the inhibitory currents was unaffected.

To determine whether spontaneous EPSCs were affected by MT-II, recordings were made from 23 retrogradely labeled DMV antrum neurons. Bath application of MT-II (100 nM) significantly decreased the mean EPSC frequency in 78\% $(n=18$ of 23) of the neurons from a baseline of $6.3 \pm 1.2$ to $4.3 \pm 1.0 \mathrm{~Hz}\left(t_{(17)}=5.1, p<\right.$ 0.0001 ), an inhibition of $32 \%$. A representative example and graph of reduction in EPSCs frequency attributable to MT-II exposure appears in Figure 8, $D$ and $E$. In the remaining $22 \%$ of the neurons $(n=$ $5 / 23$ ), MT-II significantly increased the frequency of EPSCs from a baseline value of $6.21 \pm 1.3 \mathrm{~Hz}$ to that of $8.9 \pm 1.5 \mathrm{~Hz}$ $\left(t_{(4)}=8.5, p<0.01\right)$, an increase of $43 \%$. In all neurons tested, the amplitude of EPSCs was not significantly affected by bath application of MT-II. In five separate neurons, preexposure to a mixture of TTX $(1 \mu \mathrm{M})$ plus gabazine $(10 \mu \mathrm{M})$ inhibited the effect of MT-II on sEPSC frequency.

In some neurons, the excitatory nature of the postsynaptic currents was tested by the non-NMDA antagonists CNQX (10 $\mu \mathrm{M})$ or NBQX $(5 \mu \mathrm{M})$ and AP-5 $(50 \mu \mathrm{M})$. In all neurons, these postsynaptic currents were blocked by bath application of the non-NMDA receptor antagonists.

The effect of $\alpha$-MSH on EPSCs was also tested in a separate set of DMV labeled antrum neurons $(n=5)$. Unlike MT-II, bath application of $\alpha$-MSH (500 nM) did not significantly affect either the sEPSC frequency or amplitude.

\section{Discussion}

The major findings of our study, which sought to determine the effect of stimulating MC4-Rs in the DMV and mNTS on gastric motility with MT-II and $\alpha-\mathrm{MSH}$, are summarized in Table 1.

Of the listed findings, the most significant is that microinjection of $\alpha$-MSH into the mNTS inhibits phasic gastric contractions and decreases gastric tone. We propose that these effects represent part of the output arm of the melanocortin system of the brain in that they correlate with inhibition of antral motility and fundus tone, respectively (Ferreira et al., 2002). Both effects would disrupt gastro-duodenal coordination, which would decrease gastric emptying (Ishiguchi et al., 2002; Ueno et al., 2005). 
This would be perceived as a state of satiation, hence, influencing food intake and body weight. Most important, recent data suggest that leptin increases $\alpha$-MSH in the area of the mNTS (Zheng et al., 2010). Leptin microinjected bilaterally into the arcuate nucleus of rats activates local POMC neurons, which project to the area of the NTS in which we microinjected $\alpha$-MSH. Furthermore, it decreases food intake, which is prevented by microinjection of SHU9119 into the NTS. Our novel finding shows what $\alpha$-MSH will do in the NTS when it is released, namely, inhibit gastric motility. Consistent with this are the findings that caudal brainstem administration of MC4-R ligands decrease food intake (Grill et al., 1998; Williams et al., 2000). Because both $\alpha$-MSH and MT-II inhibited phasic gastric contractions when microinjected into the mNTS, these agents would be expected to reduce food intake.

A second finding is that there are key differences between the two MC4-R agonists studied. Our initial focus was on MT-II, because it is the drug selected by many investigators to assess the role of MC4-R activation on food intake (Grill et al., 1998; Williams et al., 2000). We also studied $\alpha$-MSH because it is usually the first posttranslational peptide occurring endogenously from precursors released by POMC neurons (MacNeil et al., 2002).

Surprisingly, we noticed more differences than similarities between MT-II and $\alpha$-MSH. The most striking difference was seen in the DMV in which MT-II decreased the amplitude of phasic contractions, opposite to $\alpha$-MSH. This was unexpected because it is generally assumed that both activate the MC4-R. This difference in all respects seemed real and not attributable to an error in experimental design. In fact, we examined a wide range of doses for both peptides, and of the MT-II doses tested, only the 20 and $50 \mathrm{pmol}$ produced the characteristic inhibitory effect on gastric motility. Little or no effect was seen with lower doses of MT-II. Conversely, only stimulation of motility was seen with $100 \mathrm{pmol}$ of $\alpha$-MSH, whereas lower doses were ineffective. Potency comparisons of MT-II with $\alpha$-MSH reveal that it is 3.5 - to 134 -fold more potent than $\alpha$-MSH (Adan et al., 1999; MacNeil et al., 2002; Xiang et al., 2006). By testing many-fold lower doses of MT-II than $\alpha$-MSH without observing any significant excitatory effect, we are convinced that this difference between the two drugs is genuine. In addition, we tested the MC4-R agonist THIQ and found it to mimic the effect of $\alpha-\mathrm{MSH}$. We speculate that this difference between MT-II and $\alpha$-MSH is most likely attributable to a functionally selective agonist bias as has been reported for other receptors (e.g., such as oxytocin; Busnelli et al., 2012).

Although both peptides differentially affected gastric motility, an effect common to both at the DMV was that (unlike glutamate) they did not affect gastric tone. This "selective" effect is probably related to our finding that the DMV site responsive to both peptides is located in the medial portion of the nucleus that
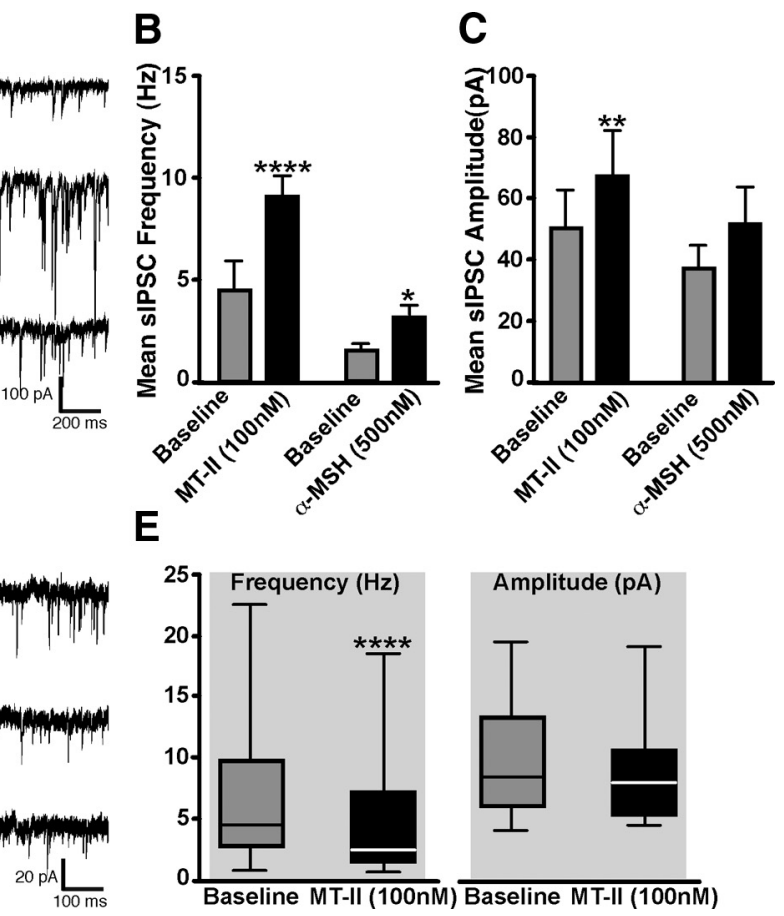

Baseline MT-II (100nM) Baseline MT-II (100nM)

Figure 8. Spontaneous EPSCs and IPSCS are affected by activation of melanocortin receptors. $\boldsymbol{A}$, Representative recordings of

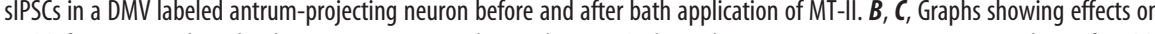
IPSCs frequency and amplitude in response to MT-II $(n=16)$ or $\alpha$-MSH $(n=5)$ exposure. $\boldsymbol{D}$, Representative recordings of sEPSCS in a DMV labeled antrum-projecting neuron before and after bath application of MT-II. $\boldsymbol{E}$, Graph illustrating the effect on sEPSC frequency and amplitude in response to MT-II exposure $(n=18) .{ }^{* *} p<0.01 ;{ }^{* * *} p<0.0001$.

Table 1. Summary of predominant effects of stimulating MC4-Rs in DMV and mNTS

\begin{tabular}{|c|c|c|c|c|}
\hline \multirow[b]{2}{*}{ Endpoint measured } & \multicolumn{2}{|l|}{ MT-II } & \multicolumn{2}{|c|}{$\alpha$-MSH } \\
\hline & DMV & mNTS & DMV & mNTS \\
\hline \multicolumn{5}{|l|}{ In vivo } \\
\hline Amplitude of phasic contractions & $\downarrow$ & $\downarrow$ & $\uparrow$ & $\downarrow$ \\
\hline Gastric tone & $\mathrm{NE}$ & NE & NE & $\downarrow$ \\
\hline Mean arterial blood pressure & $\mathrm{NE}$ & NE & NE & $\downarrow$ \\
\hline Changes in kynurenic acid response & NS & NE & NS & Yes \\
\hline \multicolumn{5}{|l|}{ In vitro } \\
\hline \multicolumn{5}{|l|}{ Firing rate of neurons (cell attached) } \\
\hline Normal-calcium ACSF & $\downarrow$ & NS & $\downarrow$ & NS \\
\hline Low-calcium ACSF & $\downarrow$ & NS & $\uparrow$ & NS \\
\hline \multicolumn{5}{|l|}{ sIPSCs } \\
\hline Frequency & $\uparrow$ & NS & $\uparrow$ & NS \\
\hline Amplitude & $\uparrow$ & NS & NE & NS \\
\hline \multicolumn{5}{|l|}{ sEPSCs } \\
\hline Frequency & $\downarrow$ & NS & NE & NS \\
\hline Amplitude & NE & NS & NE & NS \\
\hline
\end{tabular}

$\downarrow$, Decrease; $\uparrow$, increase; NE, not effected; NS, not studied.

parallels the area postrema. Neurons located at this site primarily project to the gastric antrum (Pearson et al., 2007). Incidentally, the highest density of mRNA for the MC4-R is localized to this area of the DMV (Kishi et al., 2003) as are $\alpha$-MSH-containing nerve terminals located just rostral to our MT-II/ $\alpha$-MSH injection sites (Zheng et al., 2005).

Another difference between MT-II and $\alpha-\mathrm{MSH}$ was observed in our electrophysiological studies. When presynaptic effects of the two MC4-R agonists were eliminated by perfusion with lowcalcium ACSF, MT-II produced a decrease in neural activity of DMV neurons that was indistinguishable from that obtained in normal-calcium ACSF. In contrast, $\alpha$-MSH produced a slight but statistically significant increase in neuronal firing rate. This 
difference is unlikely attributable to their concentrations because we used those used by others (Cowley et al., 1999; Fong and Van der Ploeg, 2000; Ye and Li, 2011) and were mindful that MT-II is more potent than $\alpha$-MSH. Recently, the inhibitory effects of MT-II on DMV neurons were also reported by Sohn et al. (2013), which they attributed to a PKA-dependent activation of a putative $\mathrm{K}_{\mathrm{ATP}}$ channel. Although corroboratory, comparison of our data with theirs is at present premature. Our observations are based on identified gastric antrumprojecting DMV neurons, whereas those of Sohn et al. (2013) are on cholinergic DMV neurons of unknown preganglionic origin. Altogether, our data suggest that both MT-II and $\alpha$-MSH affect DMV antrum-projecting neurons by a direct postsynaptic action.

A striking difference between MT-II and $\alpha-\mathrm{MSH}$ was also observed in the mNTS. Whereas MT-II was similar in its effect as seen at the DMV, $\alpha$-MSH exerted multiple effects. These included decreases in amplitude of phasic contractions, gastric tone, and mean arterial blood pressure. This spectrum of effects resembles those observed with $\mathrm{GABA}_{\mathrm{A}}$ antagonists in the mNTS (Herman et al., 2009). At the DMV, similar to $\alpha$-MSH, $\mathrm{GABA}_{\mathrm{A}}$ receptor blockade only enhances gastric motility (Sivarao et al., 1998). Hence, all the effects of $\mathrm{GABA}_{\mathrm{A}}$ receptor blockade at the mNTS and DMV are mimicked by $\alpha$-MSH. Furthermore, blockade of $\mathrm{GABA}_{\mathrm{A}}$ receptors at the mNTS unmasks a gastric excitatory effect of kynurenic acid (Herman et al., 2009) that is also evident with $\alpha$-MSH but not observed with MT-II. Together, these findings suggest that $\alpha$-MSH might act to suppress $\mathrm{GABA}_{\mathrm{A}}$ signaling at both the mNTS and the DMV.

Not only does $\alpha$-MSH closely match the spectrum of effects of drugs that block the $\mathrm{GABA}_{\mathrm{A}}$ receptor, but it also mimics the effects of the $\mu$-receptor agonist DAMGO at the mNTS. We recently reported that DAMGO microinjected into the mNTS decreases amplitude of phasic contractions, gastric tone, and mean blood pressure (Herman et al., 2010). Furthermore, like $\alpha$-MSH, DAMGO unmasks a gastric excitatory effect of kynurenic acid at the NTS (Herman et al., 2010). These results raise the question as to whether the effects seen with $\alpha$-MSH are via circuitry that also engages $\mu$-opioid signaling at the NTS.

Our data suggest that the two MC4-R agonists do not act in the mNTS on vagal sensory terminals to release glutamate as has been suggested by others (Wan et al., 2008). Our evidence is based in part on the dissimilar effects of MT-II and glutamate on gastric motility at this nucleus. MT-II at the mNTS only decreases the amplitude of phasic contractions, whereas glutamate additionally decreases gastric tone and mean arterial blood pressure (Cruz et al., 2007). Furthermore, in our study, kynurenic acid at the mNTS did not affect the usual decrease in phasic contractions seen after microinjection of MT-II. We could not address this question with $\alpha$-MSH because kynurenic acid displayed an excitatory effect on gastric motility in the presence of $\alpha$-MSH.

Speculating on how $\alpha$-MSH acts at the DMV to increase gastric motility, we focus on its effect on neurons in this nucleus. In the presence of low-calcium ACSF, $\alpha$-MSH increased the neuronal activity of premotor DMV neurons that project to the antrum. This direct postsynaptic effect would most likely translate into an increase in motility at the end organ. At the mNTS, $\alpha$-MSH might inhibit gastric function by suppression of the high GABAergic tone present at this site (Herman et al., 2009, 2010, 2012), which would allow for inhibitory projection neurons in the mNTS to influence premotor DMV neurons.

Addressing the inhibitory effect of MT-II on gastric motility at the mNTS, we attribute it to selective inhibition of antrum-projecting DMV neurons by activating a GABAergic mNTS-DMV circuit described previously by us (Ferreira et al., 2002; Pearson et al., 2011). Regarding the inhibition of gastric motility by MT-II at the DMV, additional studies are needed to determine the underlying mechanism(s) responsible for this phenomenon.

In summary, we set out to determine the effect of stimulating MC4-Rs in the DMV on gastric motility. We used MT-II, a drug widely used to assess the effect of MC4-R activation on food intake and body weight (Baird et al., 2011; Blevins et al., 2012; De Jonghe et al., 2012; Mul et al., 2012; Roseberry, 2013). We found its predominant effect at the DMV was to decrease the amplitude of gastric phasic contractions. A similar effect was seen in the mNTS. This is not surprising because, whereas the DMV has a high density of MC4-Rs, the NTS also displays a moderate density of MC4-Rs (Kishi et al., 2003). What changed the direction and focus of our research was the finding that the endogenous MC4-R agonist $\alpha$-MSH exerted strikingly different effects on gastric motility than MT-II. Hence, we emphasize its effects, particularly at the mNTS. Here it decreases the amplitude of phasic contraction and decreases gastric tone, affects that mimic both $\mathrm{GABA}_{\mathrm{A}}$ receptor blockers and the $\mu$-opioid receptor agonist DAMGO. These effects of $\alpha$-MSH at the mNTS are consistent with the view that its release into the mNTS via activation of a hypothalamic-NTS circuit would cause amplification of satiety signals arriving from the stomach (Zheng et al., 2010).

\section{References}

Adan RA, Szklarczyk AW, Oosterom J, Brakkee JH, Nijenhuis WA, Schaaper WM, Meloen RH, Gispen WH (1999) Characterization of melanocortin receptor ligands on cloned brain melanocortin receptors and on grooming behavior in the rat. Eur J Pharmacol 378:249-258. CrossRef Medline

Allescher HD, Daniel EE, Dent J, Fox JE, Kostolanska F (1988) Extrinsic and intrinsic neural control of pyloric sphincter pressure in the dog. J Physiol 401:17-38. Medline

Armitage AK, Dean AC (1963) Function of the pylorus and pyloric antrum in gastric emptying. Gut 4:174-178. CrossRef Medline

Baird JP, Palacios M, LaRiviere M, Grigg LA, Lim C, Matute E, Lord J (2011) Anatomical dissociation of melanocortin receptor agonist effects on tasteand gut-sensitive feeding processes. Am J Physiol Regul Integr Comp Physiol 301:R1044-R1056. CrossRef Medline

Blevins JE, Moralejo DH, Wolden-Hanson TH, Thatcher BS, Ho JM, Kaiyala KJ, Matsumoto K (2012) Alterations in activity and energy expenditure contribute to lean phenotype in Fischer 344 rats lacking the cholecystokinin-1 receptor gene. Am J Physiol Regul Integr Comp Physiol 303:R1231-R1240. CrossRef Medline

Busnelli M, Sauliere A, Manning M, Bouvier M, Gales C, Chini B (2012) Functional selective oxytocin-derived agonists discriminate between individual G protein family subtypes. J Biol Chem 287:3617-3629. CrossRef Medline

Cone RD (2005) Anatomy and regulation of the central melanocortin system. Nat Neurosci 8:571-578. CrossRef Medline

Cowley MA, Pronchuk N, Fan W, Dinulescu DM, Colmers WF, Cone RD (1999) Integration of NPY, AGRP, and melanocortin signals in the hypothalamic paraventricular nucleus: evidence of a cellular basis for the adipostat. Neuron 24:155-163. CrossRef Medline

Cruz MT, Murphy EC, Sahibzada N, Verbalis JG, Gillis RA (2007) A reevaluation of the effects of stimulation of the dorsal motor nucleus of the vagus on gastric motility in the rat. Am J Physiol Regul Integr Comp Physiol 292:R291-R307. CrossRef Medline

De Jonghe BC, Hayes MR, Bence KK (2011) Melanocortin control of energy balance: evidence from rodent models. Cell Mol Life Sci 68: 2569-2588. CrossRef Medline 
De Jonghe BC, Hayes MR, Zimmer DJ, Kanoski SE, Grill HJ, Bence KK (2012) Food intake reductions and increases in energetic responses by hindbrain leptin and melanotan II are enhanced in mice with POMC-specific PTP1B deficiency. Am J Physiol Endocrinol Metab 303:E644-E651. CrossRef Medline

el-Sharkawy TY, Morgan KG, Szurszewski JH (1978) Intracellular electrical activity of canine and human gastric smooth muscle. J Physiol 279:291-307. Medline

Fan W, Boston BA, Kesterson RA, Hruby VJ, Cone RD (1997) Role of melanocortinergic neurons in feeding and the agouti obesity syndrome. Nature 385:165-168. CrossRef Medline

Ferreira M Jr, Sahibzada N, Shi M, Panico W, Niedringhaus M, Wasserman A, Kellar KJ, Verbalis J, Gillis RA (2002) CNS site of action and brainstem circuitry responsible for the intravenous effects of nicotine on gastric tone. J Neurosci 22:2764-2779. Medline

Fong TM, Van der Ploeg LH (2000) A melanocortin agonist reduces neuronal firing rate in rat hypothalamic slices. Neurosci Lett 283:5-8. CrossRef Medline

Gillis RA, Quest JA, Pagani FD, Norman WP (1989) Control centers in the central nervous system for regulating gastrointestinal motility. In: Handbook of physiology. The gastrointestinal system (Schultz SG, Wood JD, Rauner BB, eds), pp 621-683. Bethesda, MD: American Physiological Society.

Giraudo SQ, Billington CJ, Levine AS (1998) Feeding effects of hypothalamic injection of melanocortin 4 receptor ligands. Brain Res 809:302306. CrossRef Medline

Grill HJ, Kaplan JM (2002) The neuroanatomical axis for control of energy balance. Front Neuroendocrinol 23:2-40. CrossRef Medline

Grill HJ, Ginsberg AB, Seeley RJ, Kaplan JM (1998) Brainstem application of melanocortin receptor ligands produces long-lasting effects on feeding and body weight. J Neurosci 18:10128-10135. Medline

Herman MA, Cruz MT, Sahibzada N, Verbalis J, Gillis RA (2009) GABA signaling in the nucleus tractus solitarius sets the level of activity in dorsal motor nucleus of the vagus cholinergic neurons in the vagovagal circuit. Am J Physiol Gastrointest Liver Physiol 296:G101-G111. CrossRef Medline

Herman MA, Alayan A, Sahibzada N, Bayer B, Verbalis J, Dretchen KL, Gillis RA (2010) micro-Opioid receptor stimulation in the medial subnucleus of the tractus solitarius inhibits gastric tone and motility by reducing local GABA activity. Am J Physiol Gastrointest Liver Physiol 299:G494-G506. CrossRef Medline

Herman MA, Gillis RA, Vicini S, Dretchen KL, Sahibzada N (2012) Tonic GABAA receptor conductance in medial subnucleus of the tractus solitarius neurons is inhibited by activation of mu-opioid receptors. J Neurophysiol 107:1022-1031. CrossRef Medline

Hermann GE, Travagli RA, Rogers RC (2006) Esophageal-gastric relaxation reflex in rat: dual control of peripheral nitrergic and cholinergic transmission. Am J Physiol Regul Integr Comp Physiol 290:R1570-R1576. CrossRef Medline

Iqbal J, Pompolo S, Dumont LM, Wu CS, Mountjoy KG, Henry BA, Clarke IJ (2001) Long-term alterations in body weight do not affect the expression of melanocortin receptor-3 and -4 mRNA in the ovine hypothalamus. Neuroscience 105:931-940. CrossRef Medline

Ishiguchi T, Tada H, Nakagawa K, Yamamura T, Takahashi T (2002) Hyperglycemia impairs antro-pyloric coordination and delays gastric emptying in conscious rats. Auton Neurosci 95:112-120. CrossRef Medline

Janssen P, Vanden Berghe P, Verschueren S, Lehmann A, Depoortere I, Tack J (2011) Review article: the role of gastric motility in the control of food intake. alimentary pharmacology and therapeutics 33:880-894. CrossRef Medline

Kishi T, Aschkenasi CJ, Lee CE, Mountjoy KG, Saper CB, Elmquist JK (2003) Expression of melanocortin 4 receptor mRNA in the central nervous system of the rat. J Comp Neurol 457:213-235. CrossRef Medline

Kistler-Heer V, Lauber ME, Lichtensteiger W (1998) Different developmental patterns of melanocortin MC3 and MC4 receptor mRNA: predominance of Mc4 in fetal rat nervous system. J Neuroendocrinol 10:133-146. CrossRef Medline

Lentle RG, Janssen PW, Goh K, Chambers P, Hulls C (2010) Quantification of the effects of the volume and viscosity of gastric contents on antral and fundic activity in the rat stomach maintained ex vivo. Dig Dis Sci 55: 3349-3360. CrossRef Medline

Liu H, Kishi T, Roseberry AG, Cai X, Lee CE, Montez JM, Friedman JM,
Elmquist JK (2003) Transgenic mice expressing green fluorescent protein under the control of the melanocortin-4 receptor promoter. J Neurosci 23:7143-7154. Medline

Lüdtke FE, Lammel E, Mandrek K, Peiper HJ, Golenhofen K (1991) Myogenic basis of motility in the pyloric region of human and canine stomachs. Dig Dis 9:414-431. CrossRef Medline

MacNeil DJ, Howard AD, Guan X, Fong TM, Nargund RP, Bednarek MA, Goulet MT, Weinberg DH, Strack AM, Marsh DJ, Chen HY, Shen CP, Chen AS, Rosenblum CI, MacNeil T, Tota M, MacIntyre ED, Van der Ploeg LH (2002) The role of melanocortins in body weight regulation: opportunities for the treatment of obesity. Eur J Pharmacol 450: 93-109. CrossRef Medline

Morton GJ, Cummings DE, Baskin DG, Barsh GS, Schwartz MW (2006) Central nervous system control of food intake and body weight. Nature 443:289-295. CrossRef Medline

Mountjoy KG, Mortrud MT, Low MJ, Simerly RB, Cone RD (1994) Localization of the melanocortin-4 receptor (MC4-R) in neuroendocrine and autonomic control circuits in the brain. Mol Endocrinol 8:12981308. CrossRef Medline

Mul JD, van Boxtel R, Bergen DJ, Brans MA, Brakkee JH, Toonen PW, Garner KM, Adan RA, Cuppen E (2012) Melanocortin receptor 4 deficiency affects body weight regulation, grooming behavior, and substrate preference in the rat. Obesity (Silver Spring) 20:612-621. CrossRef Medline

Pagani FD, Norman WP, Gillis RA (1988) Medullary parasympathetic projections innervate specific sites in the feline stomach. Gastroenterology 95:277-288. Medline

Paxinos G, Watson C (1998) The rat brain in stereotaxic coordinates. New York: Academic.

Pearson RJ, Gatti PJ, Sahibzada N, Massari VJ, Gillis RA (2007) Ultrastructural evidence for selective noradrenergic innervation of CNS vagal projections to the fundus of the rat. Auton Neurosci 136:31-42. CrossRef Medline

Pearson RJ, Gatti PJ, Sahibzada N, Massari VJ, Gillis RA (2011) Ultrastructural evidence for selective GABAergic innervation of CNS vagal projections to the antrum of the rat. Auton Neurosci 160:21-26. CrossRef Medline

Pedarzani P, Kulik A, Muller M, Ballanyi K, Stocker M (2000) Molecular determinants of $\mathrm{Ca}^{2+}$-dependent $\mathrm{K}^{+}$channel function in rat dorsal vagal neurones. J Physiol 527:283-290. CrossRef Medline

Rogers RC, McTigue DM, Hermann GE (1996) Vagal control of digestion: modulation by central neural and peripheral endocrine factors. Neurosci Biobehav Rev 20:57-66. CrossRef Medline

Rogers RC, Travagli RA, Hermann GE (2003) Noradrenergic neurons in the rat solitary nucleus participate in the esophageal-gastric relaxation reflex. Am J Physiol Regul Integr Comp Physiol 285:R479-R489. CrossRef Medline

Roseberry AG (2013) Altered feeding and body weight following melanocortin administration to the ventral tegmental area in adult rats. Psychopharmacology (Berl) 226:25-34. CrossRef Medline

Roselli-Rehfuss L, Mountjoy KG, Robbins LS, Mortrud MT, Low MJ, Tatro JB, Entwistle ML, Simerly RB, Cone RD (1993) Identification of a receptor for gamma melanotropin and other proopiomelanocortin peptides in the hypothalamus and limbic system. Proc Natl Acad Sci U S A 90:88568860. CrossRef Medline

Rossi J, Balthasar N, Olson D, Scott M, Berglund E, Lee CE, Choi MJ, Lauzon D, Lowell BB, Elmquist JK (2011) Melanocortin-4 receptors expressed by cholinergic neurons regulate energy balance and glucose homeostasis. Cell Metab 13:195-204. CrossRef Medline

Sahibzada N, Ferreira M Jr, Williams B, Wasserman A, Vicini S, Gillis RA (2002) Nicotinic ACh receptor subtypes on gastrointestinally projecting neurones in the dorsal motor vagal nucleus of the rat. J Physiol 545:10071016. CrossRef Medline

Shapiro RE, Miselis RR (1985) The central organization of the vagus nerve innervating the stomach of the rat. J Comp Neurol 238:473-488. CrossRef Medline

Sivarao DV, Krowicki ZK, Hornby PJ (1998) Role of GABAA receptors in rat hindbrain nuclei controlling gastric motor function. Neurogastroenterol Motil 10:305-313. CrossRef Medline

Sohn JW, Harris LE, Berglund ED, Liu T, Vong L, Lowell BB, Balthasar N, Williams KW, Elmquist JK (2013) Melanocortin 4 receptors reciprocally regulate sympathetic and parasympathetic preganglionic neurons. Cell 152:612-619. CrossRef Medline 
Travagli RA, Hermann GE, Browning KN, Rogers RC (2006) Brainstem circuits regulating gastric function. Annu Rev Physiol 68:279-305. CrossRef Medline

Ueno T, Uemura K, Harris MB, Pappas TN, Takahashi T (2005) Role of vagus nerve in postprandial antropyloric coordination in conscious dogs. Am J Physiol Gastrointest Liver Physiol 288:G487-G495. CrossRef Medline

Wan S, Browning KN, Coleman FH, Sutton G, Zheng H, Butler A, Berthoud HR, Travagli RA (2008) Presynaptic melanocortin-4 receptors on vagal afferent fibers modulate the excitability of rat nucleus tractus solitarius neurons. J Neurosci 28:4957-4966. CrossRef Medline

Williams DL, Kaplan JM, Grill HJ (2000) The role of the dorsal vagal complex and the vagus nerve in feeding effects of melanocortin-3/4 receptor stimulation. Endocrinology 141:1332-1337. CrossRef Medline

Xiang Z, Litherland SA, Sorensen NB, Proneth B, Wood MS, Shaw AM, Millard WJ, Haskell-Luevano C (2006) Pharmacological characterization of 40 human melanocortin- 4 receptor polymorphisms with the en- dogenous proopiomelanocortin-derived agonists and the agouti-related protein (AGRP) antagonist. Biochemistry 45:7277-7288. CrossRef Medline

Ye ZY, Li DP (2011) Activation of the melanocortin-4 receptor causes enhanced excitation in presympathetic paraventricular neurons in obese Zucker rats. Regul Pept 166:112-120. CrossRef Medline

Zheng H, Patterson LM, Phifer CB, Berthoud HR (2005) Brain stem melanocortinergic modulation of meal size and identification of hypothalamic POMC projections. Am J Physiol Regul Integr Comp Physiol 289:R247-R258. CrossRef Medline

Zheng H, Patterson LM, Rhodes CJ, Louis GW, Skibicka KP, Grill HJ, Myers MG Jr, Berthoud HR (2010) A potential role for hypothalamomedullary POMC projections in leptin-induced suppression of food intake. Am J Physiol Regul Integr Comp Physiol 298:R720-R728. CrossRef Medline

Zhou SY, Lu YX, Owyang C (2008) Gastric relaxation induced by hyperglycemia is mediated by vagal afferent pathways in the rat. Am J Physiol Gastrointest Liver Physiol 294:G1158-G1164. CrossRef Medline 